
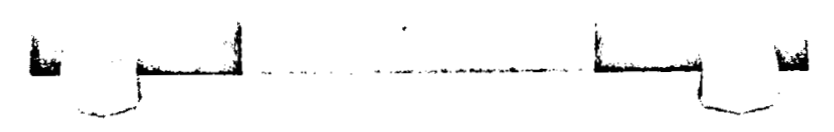

\author{
SPECTROSCOPIC STUDY OF THE GAS CAP RADIATION INTIENSITY \\ FOR STMULATED MARTIAN ATMOSPHERIC PROBES
}

\author{
By Warren Winovich ${ }^{2}$ and Paul A. Croce ${ }^{2}$ \\ Ames Research Center, NASA \\ Moffett Field, Califormia
}

\title{
INTTRODUCTION
}

A high velocity probe launched into an atmosphere of unknown composition offers a unique opportunity to obtain spectrographic information by close-range examination of the radiating species in the shock-heated gas cap. This information can establish the constituents present, and also can yield relative concentrations of the planetary gas mixture. This knowledge could materially aid in the reduction and interpretation of data from other onboard experiments. Such information would prove vital for planning of tuture space missions and would materially aid in the design of iuture manned and unmanned vehicles.

The recent Mariner IV experiments, reference 1, and the earthbased spectroscopic measurements of IR, reference 2, and UV scatter $J$ ing, reference 3, suggest that the Mars atmosphere contains at least 33 percent carbon dioxide. The remaining constituents are postulated to be nitrogen and argon. These latter two have not been detected lut are tentatively assigned as constituents on the

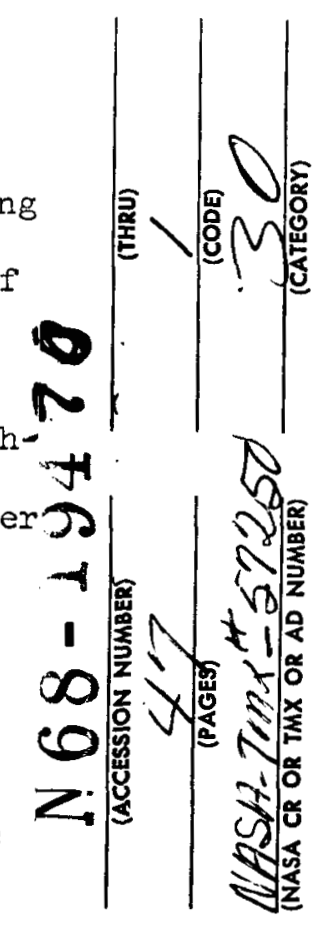

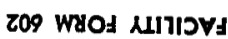

$I_{\text {Research Scientist }}$

${ }^{2}$ lst It., Department of the Army, Military Assignment at Ames 


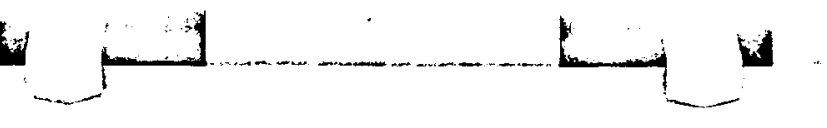

$-2-$

basis of abundancy considerations, reference 4, and postulated geological activity.

Seiff and Reese, reference 5, recently pointed out that instrumented, spherically shaped probes of low ballistic coefficient represent a practical design for a Martian atmosphere probe. Typically, a spherical nose radius of the order of $30 \mathrm{~cm}$ can be employed. According to the theoretical predictions of Boobar and Foster, reference 6, and the free-flight-range measurements of James, reference 7, the cyanogen formed in the hightemperature gas cap appears to be one of the promising candidates for spectral examination during entry into the Martin atmosphere. The planetary space probe is designed to make a steep entry $\left(70^{\circ}-90^{\circ}\right)$ into the atmosphere. Figure 1 illustrates the convective heat-transfer rate as a function of velocity that one calculates for such an entry into an atmosphere of 46 percent $\mathrm{CO}_{2}, 23$ percent $\mathrm{N}_{2}$, and 31 percent $A$. The entry velocity of $6.7 \mathrm{~km} / \mathrm{sec}$ is taken to be representative for a 1969 launch. For the steep entry angle contemplated, and for the $30-\mathrm{cm}$ radius spherical nose, maximum convective heating occurs almost simultaneously with maximum radiative heating. If an ablative heat shield is employed, the problem arises as to the effect of radiation from the ablation vapors upon the detection of gas-cap radiation, because it is necessary to measure the gas-cap radiation by looking out from within the model into the stagnation zone. A plasma-tunnel study of gas-cap and 


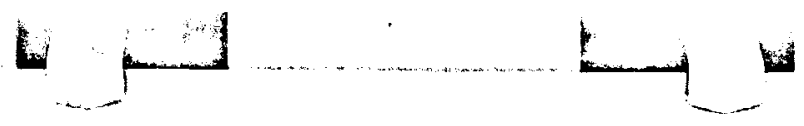

$-3-$

ablation-products radiation in a simulated Martian atmosphere forms the subject matter of the present paper.

\section{TEST FACILITY}

A schematic view of the plasma-tunnel facility is shown in figure 2. Details of the facility may be found in reference 8. Briefly, it consists of a Delaval nozzle having a throat diameter of $1.27 \mathrm{~cm}$ and having provisions for sustaining a D.C. electric are between electrodes in the high pressure plenum chamber on the left and the exit of the supersonic nozzle on the right. The metered gas mixture is introduced into the plenum chamber just downstream of the cathode shroud and is heated by the electrical cischarge in the constrictor section. The nozzle exit is $15.2 \mathrm{~cm}$ in diameter and the flow exhausts into an evacuated test chamber. The test chamber pressure was maintained at a low value by a steam ejector system such that the free jet was approximately balanced. For these conditions a test body with 45 percent blockage can be employed with steady, uniform flow existing at the stagnation region.

TEST BODY AIVD INSTRUMENTATION

The test body used for this study is shown in figure 3 . It consists of a flat-faced cylindrical nose of $10 \mathrm{~cm}$ diameter and a 15-degree conical afterbody. The flat-faced nose has corner 

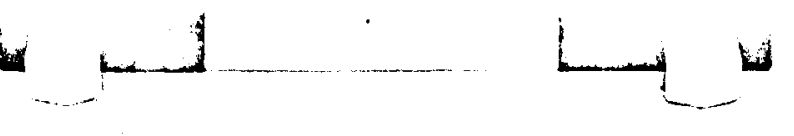

$-4-$

rounding sufficient to match the velocity gradient at the stagnation point with that of a $30-\mathrm{cm}$ radius sphere. This shape was arrived at by trial with a pressure-instrumented model. Interchangeable nose sections of various ablation and heat-sink materials were provided.

The conical afterbody contained the source optics system. The 15-degree displacement of the optical axis with respect to the axis of symmetry was necessary to avoid collecting the high intensity radiation from the arc constrictor. A collimating system Incorporating a small aperture limited the region viewed and eliminated the background radiation. Details of the collimated collection-optics system are contained in Appendix A. The 15-cm diameter afterbody expanded the flow to a thin tenuous layer over the short, cylindrical skirt just upstream of the base, which insured that the transmitted radiation consisted primarily of stagnation-point radiation. Tests with the source optics blocked insured that no measurable radiation was received from regions other than the stagnation zone.

Figure 4 compares various parameters calculated for the contemplated full scale entry with those selected for the plasma-tunnel simulation tests. The items of importance for radiation test simulation are the velocity, density, and shock stand-off distance. As shown on the figure, all are matched except the density which is a factor of 30 low. This mismatch in density is equivalent to 


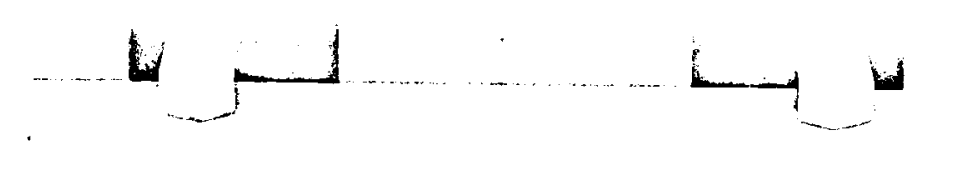

\section{$-5-$}

an increase in altitude of about $27 \mathrm{~km}$ ( $8 \mathrm{~km}=$ scale $\mathrm{ht}$ ) over the altitude at the peak heating condition. It corresponds to a point in time on the entry trajectory 4 seconds prior to peak radiation heating. Consequently, the test conditions correspond directly to an expected full-scale situation, but not the most severe. Referring to figure $I$ again, the test conditions fall within the stippled area shown on the trajectory curve. For the test conditions, figure 5 illustrates the test body with the radiating gas cap for the case of a non-ablating copper wall.

Instmmentation for the tests is shown in figure 6 . The source optics within the test body directs radiation from the gas cap out the rear flange via a first-surface mirror. After passing through the wind tunnel port, the radiation is reflected to a cylindrical first-surface mirror where the circular beam is Wused as a line on the entrance slit of a spectrograph. The spectrograph had a focal ratio of 6.8 and was equipped with a 1200 groove/m grating blazed at $3500 \AA$. The gas-cap spectra in the range 2700 to $6500 \AA$ were recorded by means of photographs. The plates were calibrated with the model in place by directing a collimated beam from a tungsten ribbon filament lamp into the source optics. The radiative intensity of the tungsten filament was determined by measuring brightness temperature with an optical pyrometer and by recourse to the emissivity data of Larrabee (ref. 9) to obtain a blackbody temperature. Details of the calibra- 


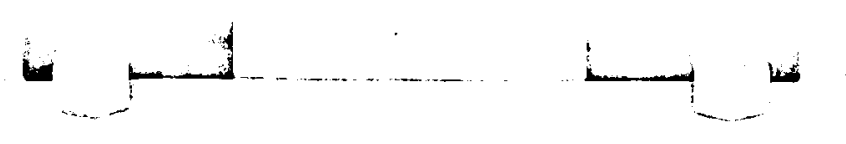

\section{$-6-$}

tion are given in Appendix B.

The film was Kodak Spectrographic plate film type $103 \mathrm{~F}$. Exposure times for both tests and calibrations were such that the reciprocity law, i.e., $I \times T=$ const., pertains for the photographic emulsion. Photographic densities were read with a Joyce Loebel microdensitometer.

\section{RESULTS AND DISCUSSION}

The gas-cap radiation was measured in the arc-jet facility for non-ablating and ablating surfaces. Experimental results for a non-ablating copper surface are shown in figure 7. Total radiation per unit volume is plotted against velocity. The effect of

shock ree-stream density is accounted for by using the correlating parameter suggested by theoretical calculations (refs. 10 and 11). The gas mixture consisted of 46 percent $\mathrm{CO}_{2}, 23$ percent $\mathrm{N}_{2}$, and 31 percent Argon (percents by volume). The present results are compared with the molecular theory prediction for $\mathrm{CO}_{2}-\mathrm{N}_{2}$. mixtures of reference 10. The theory has been adjusted to correspond to the same percentages (by volume) as the test gas (i.e., 45 percent $\mathrm{CO}_{2}, 23$ percent $\mathrm{N}_{2}, 31$ percent A). This adjustment was made by applying ( 1 ) the experimental correlation obtained by Janes (ref. 7) for concentration effects and (2) the theoretical dilution correlation of reference 10 . The ballistic range and shock tube data of references 7,10 , and 12 with no argon dilution 


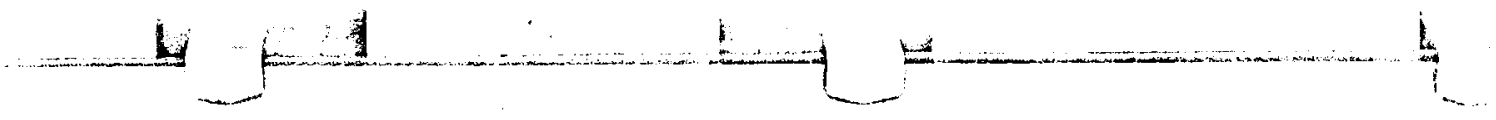

are also shown. The theory of reference 10 agrees well with these results. The present data also show the predicted trend With velocity and agree 'with the dilution effect of argon predicted by the theory of reference 10. The adjusted theoretical curve which applies to the present gas mixture differs by factors of 2.5 at $5 \mathrm{~km} / \mathrm{sec}$ to 1.2 at $7 \mathrm{~km} / \mathrm{sec}$. Possible explanations

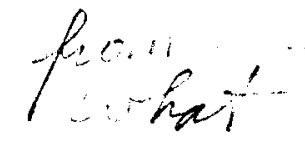
for this discrepancy are considered below.

The present data were obtained for values of density ratio suificiently low to match the contemplated density ratios $\left(10^{-5}<\rho_{\infty} / \rho_{0}<10^{-3}\right)$ during the time preceeding maximum gas-cap radiation for the Mars probe entry. As noted above, for these Iori densities the, data are only in reasonable agreement with equilibriun theory, whereas the ballisuic range and shock tube cata which generally agree closely with theory were obtained at Iniciently high density and scale to insure equilibrium.

Tonequilibrium effects in the present results were assessed by ssuming that $\mathrm{CN}$ forms accoraing to $\mathrm{CO}+\mathrm{N} \rightleftarrows \mathrm{CN}+0$. For this reaction, the CN formation is limited by the concentration of $\mathrm{CO}$. For this chemical model, the relaxation distance for the reaction $\mathrm{CO}_{22} \rightleftarrows \mathrm{CO}+\mathrm{O}$ can be found from reference 13. For the present dessity range $\left(\rho_{\infty} / \rho_{0}=1-5 \times 10^{-5}\right)$ a 50 percent change in the concentration of $\mathrm{CO}$ in the stagnation region will occur in a distiance of $20 \mathrm{~m}$, which is approximately equal to the shock stand. off distance. In the plasma tunnel, expansion occurs only to a 

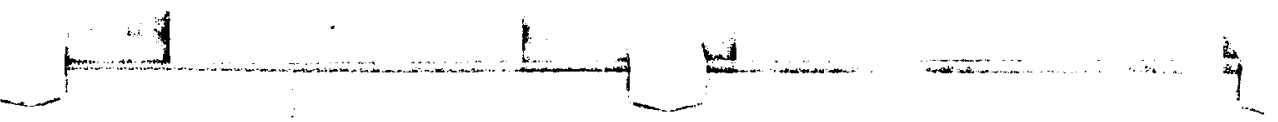

$-8-$

Mach number of 6.2. Accordingly, at operating conditions of 13.4 $\mathrm{Mj} / \mathrm{kg}(5.10 \mathrm{~km} / \mathrm{sec})$ the free stream is predissociated to a value of $z=1.40$ as compared to the equilibrium value at the stagnation state of $z=1.90$. On the basis of the free stream predissocietion level, the $\mathrm{CN}$ concentration behind the bow shock has been estimated to be 87 percent of the equilibrium value. Consequently, the radiation, assumir corsiant temperature, is preaicted to be a factor of $1.2\left(=0.87^{-\cdots 0}\right)$ bels. equilibriun values. Tris nactor accounts for the aiscreparer at high velocity $(6.85 \mathrm{~km} / \mathrm{sec})$ but does not completely account for the iscrepancy at lai velocities.

Although an ablating heat shield would reduce probe launch we-ght, ablation vapor formation car drastically affect the gascap spectra. The radiation characteristics for various heat $\therefore$ ield materials were assessed in ges mixtures that consisted of $62 / 3$ percent $\mathrm{CO}_{2}, 91$ percent $\mathrm{N}_{2}$, and $21 / 3$ percent $\mathrm{A}$ (by volume). Figure 8 presents spectra of the gas cap for the non-ablating copper nose and for several plastic heat shield materials. The wavelength range of the spectrograms is from 3500 to $6700 \AA$. For the non-ablating copper surface the radiative flux is due almost solely to the CN violet band system. The three lower spectra are for exactly the same flow conditions but with surfaces of polyethylene, polytetrafluoroethylene, and polyformaldehyde. The gas-cap spectra are quite similar for each of the three plastics. 


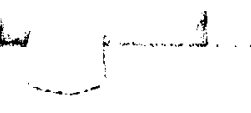

$-9-$

In addition to enhanced $\mathrm{CN}$ violet radiation, the ablation-vapor rediation consists of $\mathrm{C}_{2}$ Swan band radiation and the $\mathrm{C}_{2}$ HighPressure band system. The hydrocarbon plastics also display a prominent CH $4300 \AA$ band series ana appreciable hydroge: radiation: A trace amount of hydroren appears in ca $3.10 \%$ Por tis copper surface.

Eecause the $\mathrm{CN}$ violet band systom apperss to ba vell uncer$x$ ani amenable to analysis both $\vdots$ terms of species concerum-

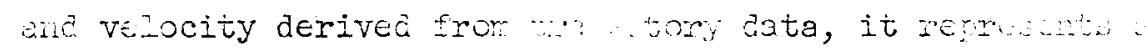
… ....ukiate for monitoring ratition uring entry into an aneprere with $\mathrm{CO}_{2}$ and $\mathrm{i}$ a $\mathrm{kin}$ inates. However, the plasma trimel tests indicate sizable enhancement of the CN violet system $y \quad$ a zresence of ablation eject: ir the bourdary layer. The a.....uersent of the CN violet systew the ablators is shown in

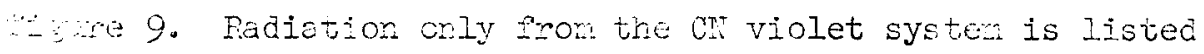
chative to the non-ablating copper surface. All of the plastic oblators increasec the on viclet band system raciation by approximately the sane amount (valiues range from 3 to 4 ). These data are apparently contrary to ballistic range and shock tube data Wich show little or no increase in total radiation with polytetrafluoroethylene and polyformaldehyde models (refs.7 and 14). In the following discussion ablation measurements from an air study are used to show that there is in Iact no inconsistency and that 


\section{ot ho bo}

one can estimate the ablation vapor radiation relative to the gascap radiation.

The effect of body radius on the intensity of radiation from an ablating body is illustrated in figure 10. The integrated total intensity over the wavelength range 3600 to $6700 \AA$ is compared for polyethylene models of several radii operated in a plasma tunnel $\therefore \tau$ constant conditions. These tests were performed in air using polyethylene models of the same blunt shape but with smaller radii. The effects of muning in air rather than in $\mathrm{CO}_{2}-\mathrm{N}_{2}-\mathrm{A}$ mixtures is considered to be unimportant here since only relative changes in the ablation vapor zone radiation were considered. Moreover, the present measurements indicated that the gas-cap radiation forms a celatively small part of the total observed radiation for both flows. Therefore, the scaling law for ablation vapor radiation will aepend only weakly on the main flow constituents. Since conditions were constant, the change in radius for this series is equivalent to a change in convective heating rate (ref. 15). The data are shown normalized to the intensity for the smallest model $(6.2 \mathrm{~mm})$. The solid line shown represents the predicted scaling law for ablation vapor zone radiation derived in Appendix $C$ (equation $\mathrm{C}-9$ ). The experimental trend agrees well with the approximate formulation.

Using the measured enhancement of radiation for ablation of polyethylene (fig. 9), the scaling law for ablation vapor radiation 


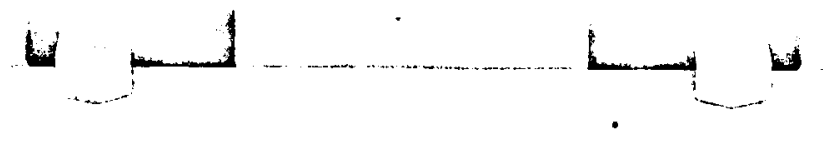

\section{$-11-$}

(equation C-16) and for the gas-cap radiation (fig. 7) can be used to predict the relative intensities for gas-cap radiation as compared to the total radiation received. The approximate scaling law has been applied to typical ballistic range measurements and to the contemplated Mars entry (fig. 1). All comparisons are for a velocity of $5.6 \mathrm{~km} / \mathrm{sec}$. The results of such a calculation are shown in figure 11. For the cases illustrated, the contribution of gas-cap radiation is shown. Thus, for plasma tunnel tests with ablation the gas-cap radiation--which would represent the signal one wishes to analyze--is only $1 / 4$ of the total signal. On the other hand, the ballistic range data will contain less than 10 percent contribution from ablation vapors. Plastic models, therefore, can be used in ballistic ranges with negligible uncertainty regarding the radiation source. Finally, for the contemplated full-scale case at peak heating, there is a 20 percent contribution from the ablation vapor zone, while at an earlier time in trajectory (4 seconds prior) there is over a 70 percent contribution. The ablative heat shield would give a signal that contains a variable amount of ablation vapor zone contribution which would introduce uncertainty into the interpretation of the gas-cap constituents for the Mars atmosphere. For this reason, atmospheric probes should probably incorporate heat-sink shields to prevent gas-cap contamination with ablation vapors and thus avoid uncertainties in the interpretation of spectral measurements. 


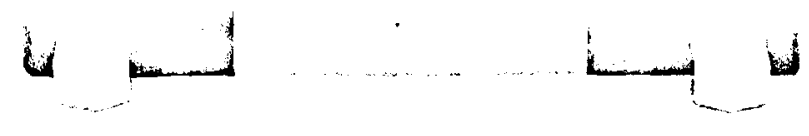

$-12-$

\section{CONCLUDING REMARKS}

1. Radiation from $\mathrm{CO}_{2}-\mathrm{N}_{2}-\mathrm{A}$ mixtures appears to be well understood. Tests approaching equilibrium conditions in the gas cap agree well with theory (when intensities are normalized with respect to density rather than pressure as pointed out in rei. 11), suggesting that $\mathrm{CN}$ violet radiation may be an important tool for probing distant planetary atmospheres with $\mathrm{CO}_{2}$ and $\mathrm{N}_{2}$ as constituents.

2. Ablative heat shield materials suistantially alter the total radiation. Ablation ejecta can increase the observed intensities of the CN violet system by as much as a factor of 4-depending on the free-stream density at the time of measurement. For this reason, atmospheric probes should probably incorporate heat-sink shields to prevent gas-cap contamination with ablation vapors and thus avoid uncertainties in the interpretation of spectral measurements.

3. Proper scaling of density and body radius (i.e., convective heating rate) is required to simulate radiative intensities for planetary entrles where peak heating rates are not high (such as a Mars entry). This is essential in view of the significant contribution to radiation that is possible from the ablation ejecta in the stagnation region. Moreover, nonequilibrium concen- 


\section{$4-1+L$}

\section{$-13-$}

tration of the molecules at low densities can appreciably alter the emitted radiation. 

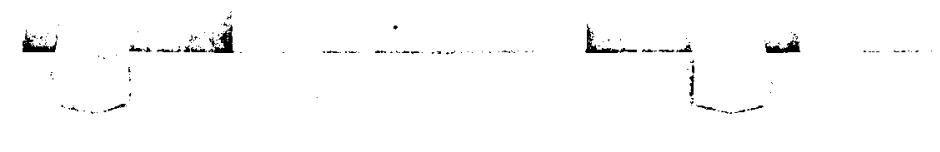

REFETRENCES

1. Kliore, A., Cain, D. L., Levy, G. S., Eshleman, U. R., Fjeldbo, G., and Drake, F. D.: Occultation Experiment: Results of the First Direct Measurements of Mars' Atmosphere and Ionosphere; Science, Vol. 149, No. 3689, September 10, 1965.

2. Kaplan, I. D., Munch, G., Spinrad, H.: Kstrophysies Journal, Vol. 139, No. 1 (1964).

3. Ivans, D. C.: Ultraviolet Ferlectivity os virs, Science, rol. 149, No. 3687, August 27, 196;.

$\therefore$ Menzel, H.: Our Sur, Harvarỏ University Series, 1950.

5. Seiff, A., ana Reese, D. E.: Banining Mars' Atmosphere, Astro. and Aero., February $=j 55$.

6. Boobar, M. G., and Foster, R. M.: Some Aerothermodynamic Considerations for Martian Entry and Heat Shield Design, IAS Paper 62-163 (1962).

7. James, C. S.: Experimental Study of Radiative Transport from Hot Gases Simulating ir Composition the Atmospheres of Mars and Venus, AIAA Journal, Vol. 2, No. 3, March 1964.

8. Stine, H. A., Watson, V. R., and Shepard, C. I.: Effect of Axial Flow on the Behavior of the Wall-Constricted Arc; Agardograph 84; September 1964.

9. Iarrahee, R. D.: Snectral Fmissivity of Tungsten, Tournal of the Optical Society of America, Vol. 49, No. 6, June 1959.

10. Arnold, J. O., Reis, V. H., and Woodward, H. T.: Studies of Shock-Layer Radiation of Bodies Entering Planetary Atmospheres, AIAA JournaI, Vol. 3, No. 11, November 1965.

11. Wolf, F., and Horton, T.: Effect of Argon Addition on ShockLayer Radiance of $\mathrm{CO}_{2}-\mathrm{N}_{2}$ Gas Mixtures, AIAA Journal, Vol. 2, No. 8, August 1964.

12. Thomas, G. M., and Menard, W. A.: Total Radiation Heat Transfer Gage for Hypervelocity Shock Tube Experiments, JPL TR No. 32-636, August 1964 . 

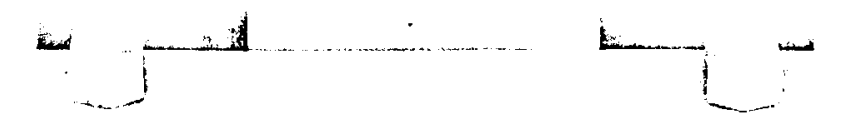

$$
-15-
$$

13. Howe, J. T., Viegas, J.R., and Sheaffer, Y. S.: Study of the Nonequilibrium Flow Field Behind Normal Shock Waves in Carbon Dioxide, NASA TN D-1885, June 1963.

14. Steinberg, M., Maiden, C. J., Leak, W. R., and Hansen, C. F.: Preliminary Studies of the Effects of Ablation Contaminants on Radiation, General Motors Defense Res. Lab. Report TR 62209 H, December 1962.

15. Marvin, J. G., and Deiwert, G. S.: Convective Heat Transfer in Planetary Gases, NASA TR R-224, July 1965.

16. Katzen, E. D., and Kaattari, G. F.: Inviscid Hypersonic Flow Around Blunt Bodies, AIAA Jownei, Vol. 3, No. 7, July 1965.

17. Bailey, H. E.: Equilibrium Themocmaric Properties of Three Engineering Models of the Martiki tnosphere, NASA SP-3021, 1965.

18. Rohsenow, W. M., and Choi, H. Y.: Heat, Mass, and Momentum Transfer, Prentice-Ha11, 1961.

19. Rutgers, G. A. W., and DeVos, J. C.: Relation Between Brightness Temperature, True Temperature, and Colour Temperature of Tungsten, Physica XX, 1954.

20. Gruszczynsk1, J. S., and Warren, W. R.: Experimental HeatTransfer Studies of Hypervelocity Flight in Planetary Atmospheres, AIAA Journal, Vol. 2, No. 9, September 1964.

21. Boison, J. C., and Curtiss, H. A.: An Experimental Investigation of Blunt Body Stagnation Point Velocity Gradient, ARS Journal, Vol. 29, No. 2, February 1959.

22. Van Dyke, M. D., and Gordon, H. D.: Supersonic Flow Past a Family of Blunt Axisymetric Bodies, NASA TR R-1, 1959.

23. Craig, R. A., and Davy, W. C.: Thermal Radiation from Ablation Products Injected into a Hypersonic Shock Layer, NASA TN D1978, September 1963. 


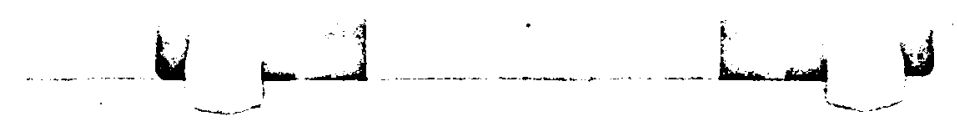

is

\section{ACKNOWLEDGMETT}

The authors are deeply indebted to Nr. Walter stevens for his invaluable assistance in performing these tests. 

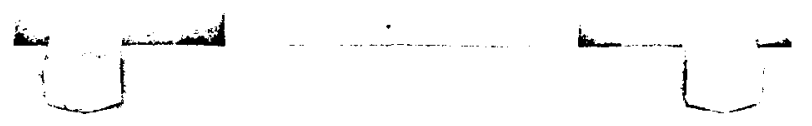

IIST OF FIGURES

Figure 1. - Convective heating rate for a sphere entering a simulated Mars atmosphere.

Figure 2. - Constricted-arc plasma tunnel.

Figure 3. - Test body.

Figure 4. - Simulation parameters.

Figure 5. - Gas-cap radiation.

Figure 6. - Experimental arrangement.

Figure 7. - Correlation of gas-cap radiation for non-ablating surface.

Figure 8. - Gas-cap spectra for non-ablating and ablating surfaces.

Figure 9. - Fnhancement of CN violet band system due to ablation.

Figure 10.- Effect of body radius on radiative intensity for ablating polyethylene models.

Figure 11. - Predicted ratio of gas-cap radiation to total radiation for polyethylene surface. 
HETING RATE FOR A SPHERE ENTERNG SMULATED NARS ATMOSPHERE.

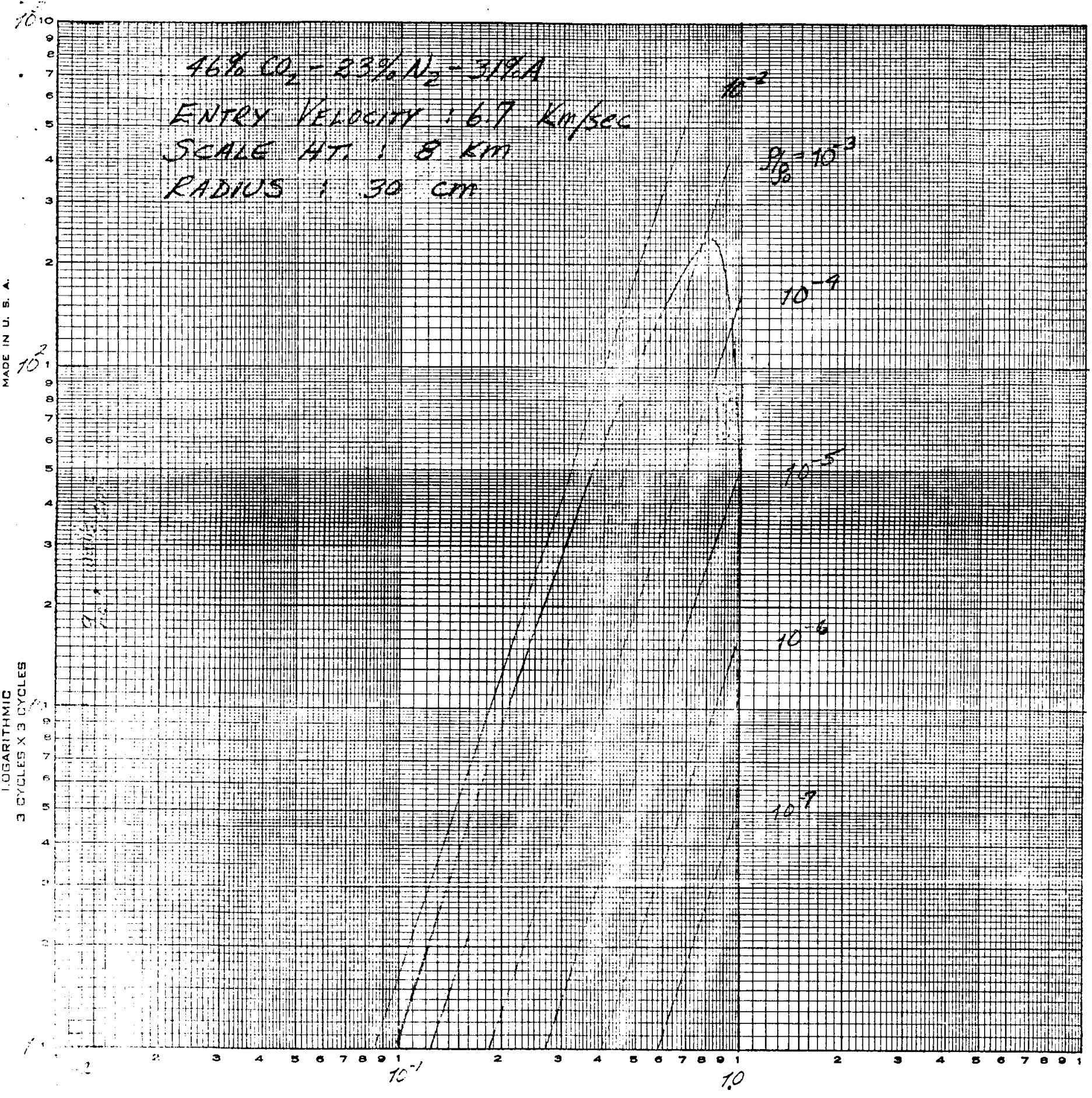


$\frac{1}{3}$
$\frac{2}{2}$
$\frac{5}{4}$
$\frac{5}{5}$
0

$\frac{u}{\alpha}$

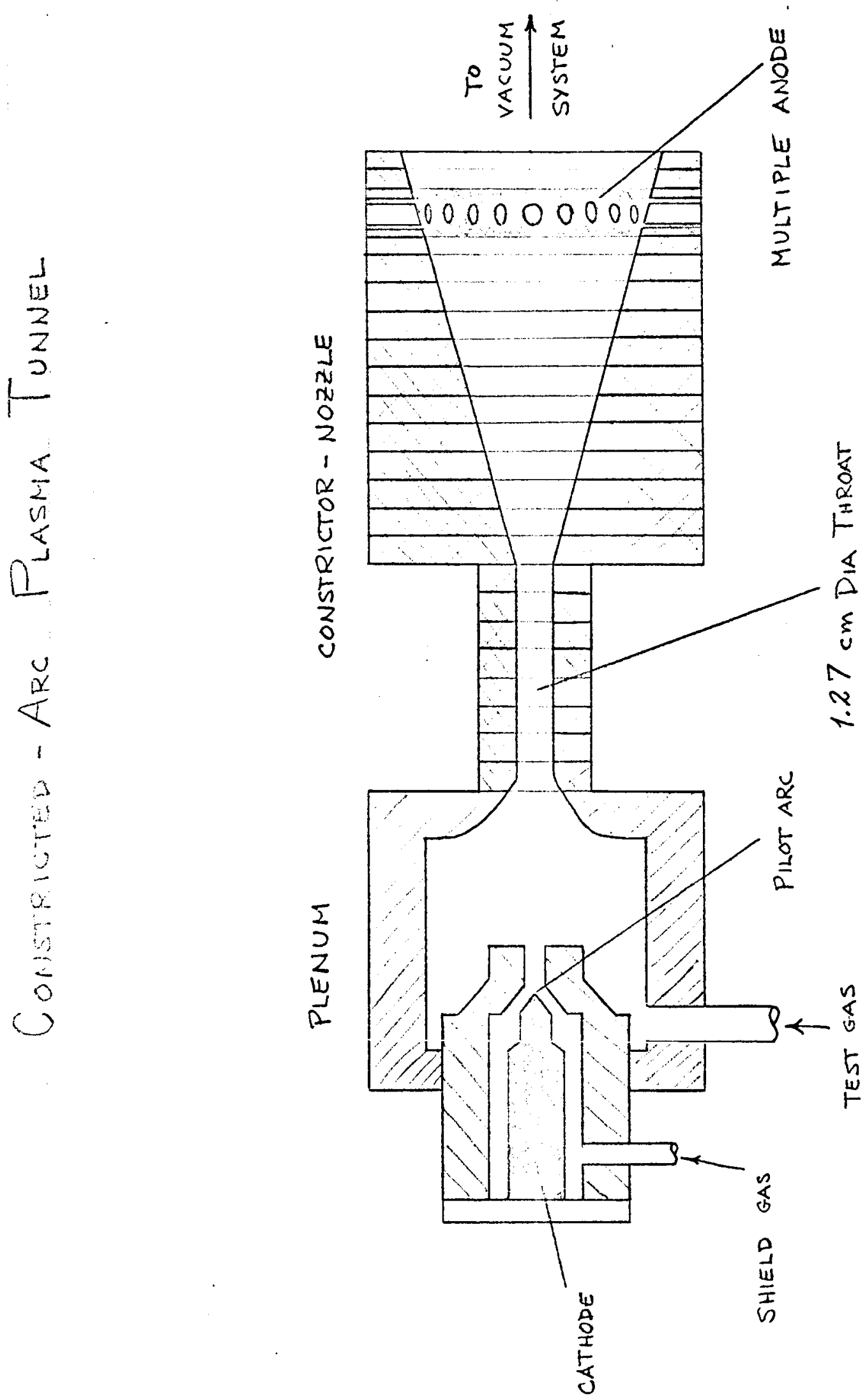

r 

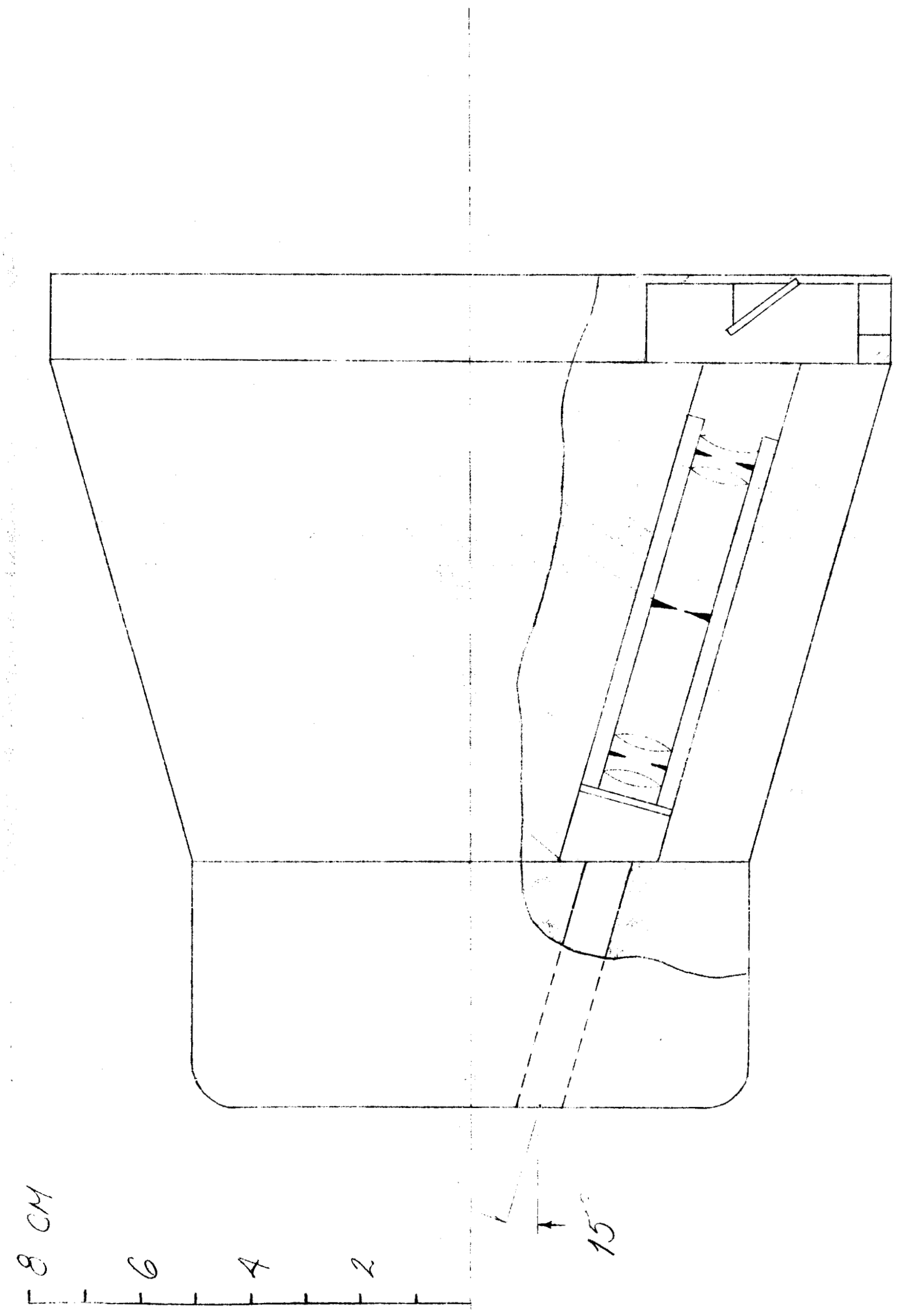


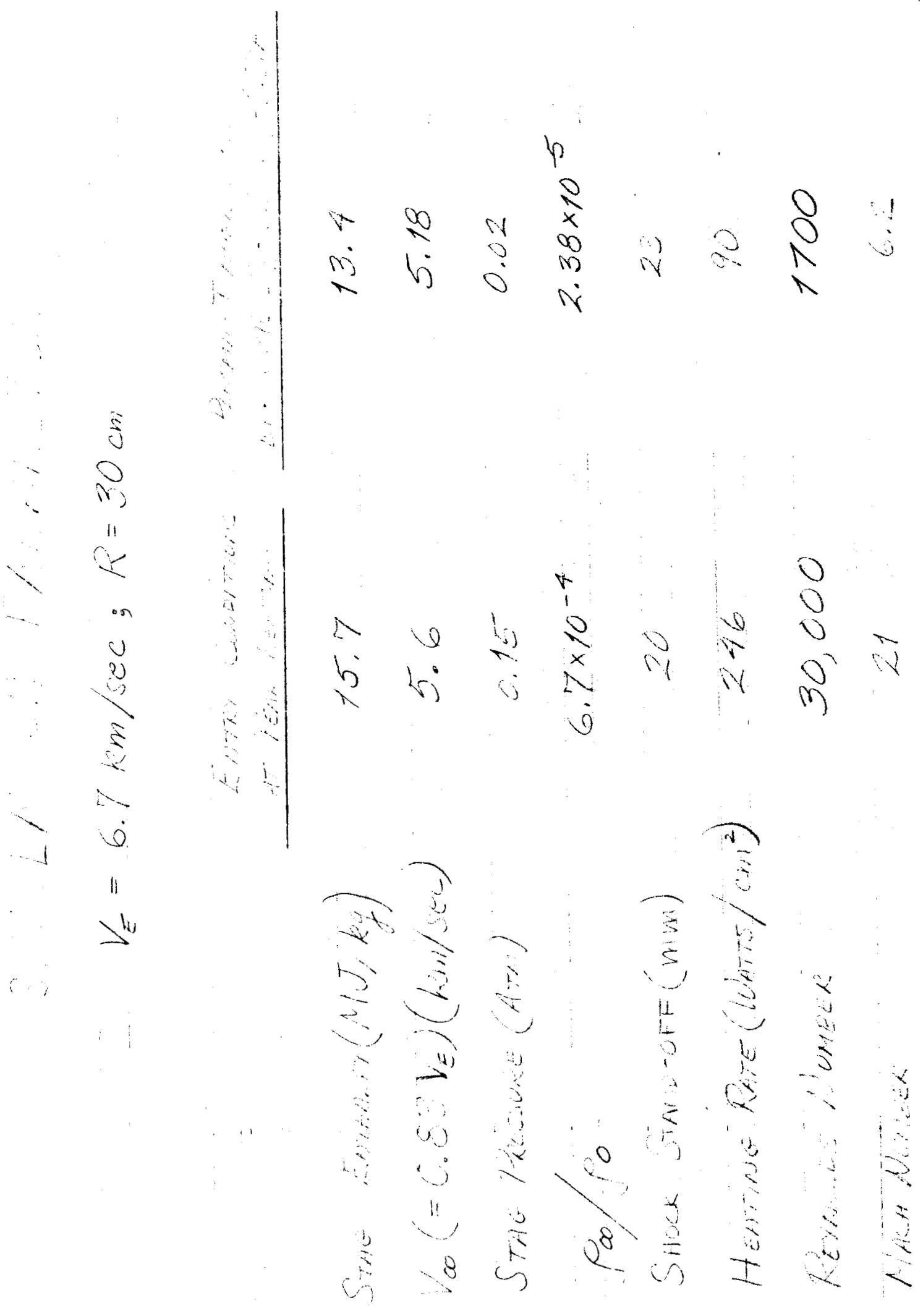


figure 5. gas cap radiation

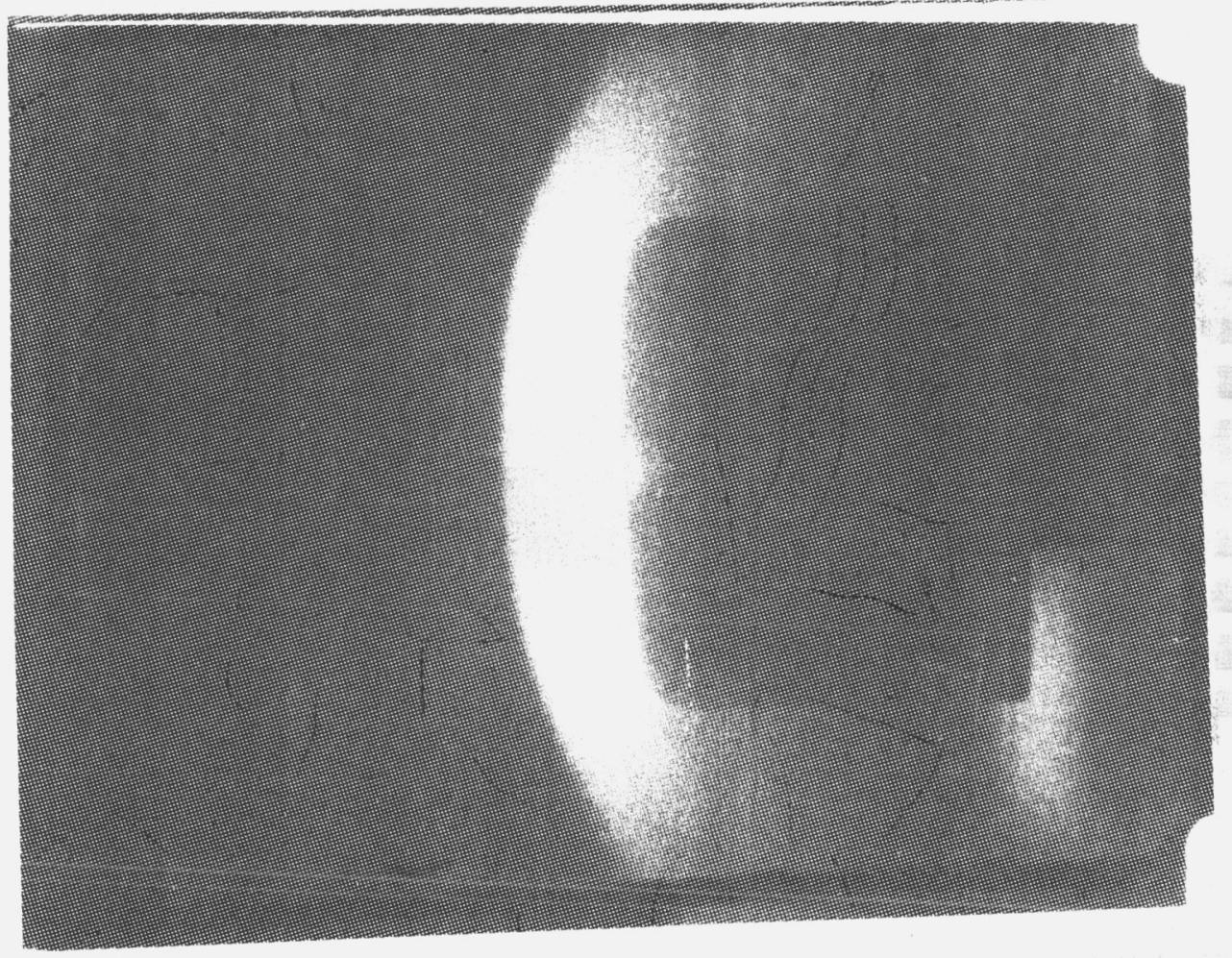




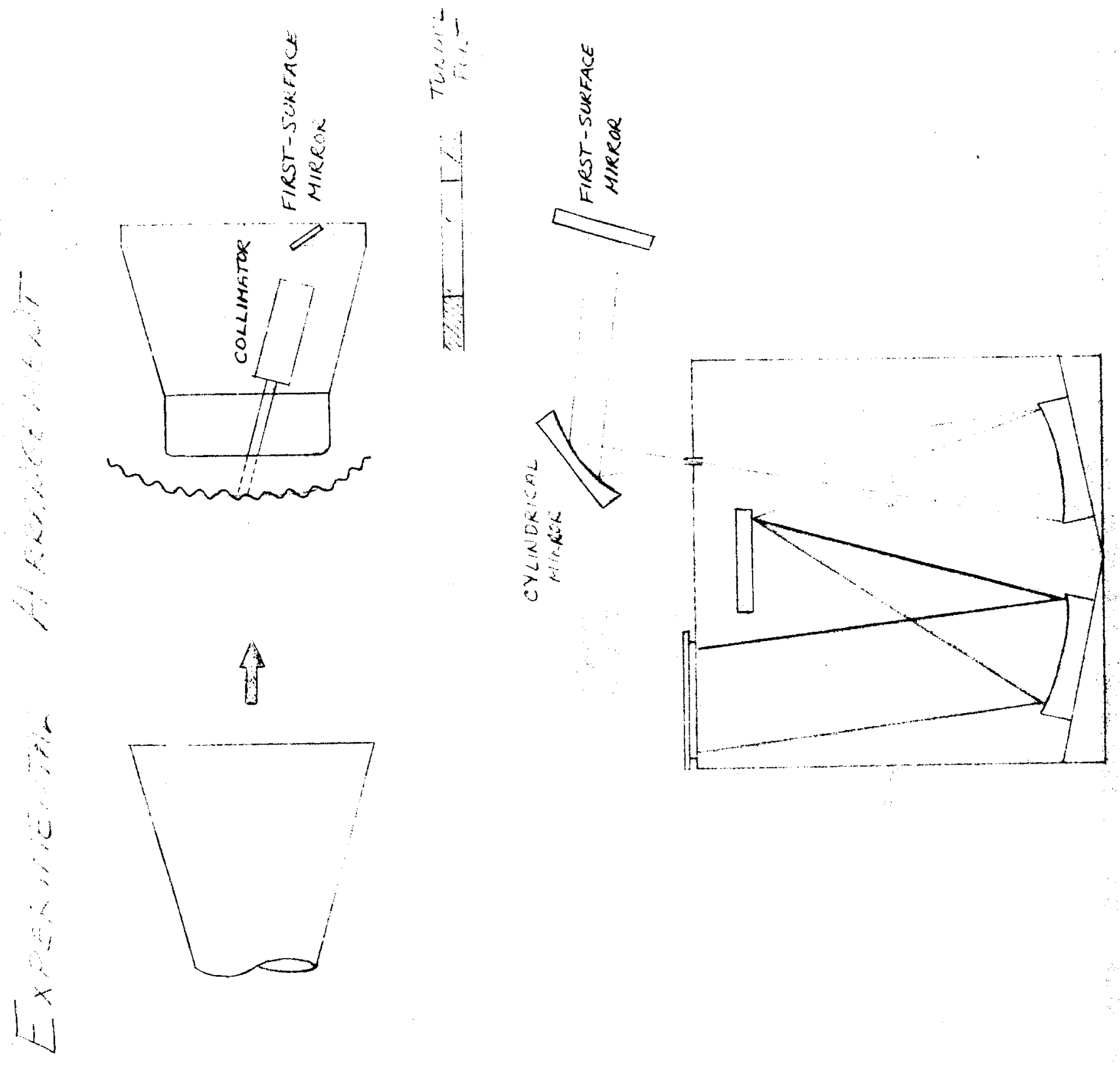




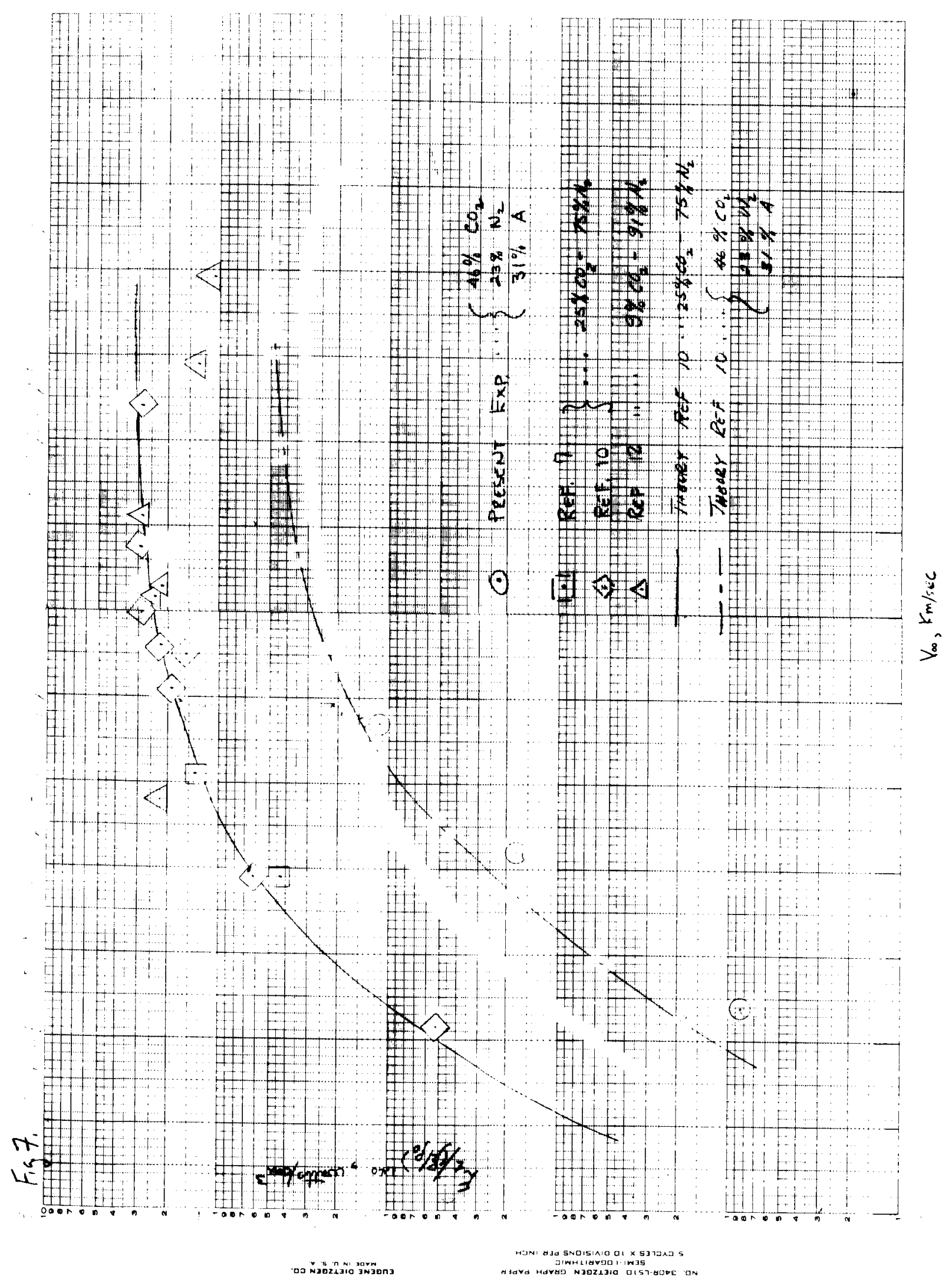




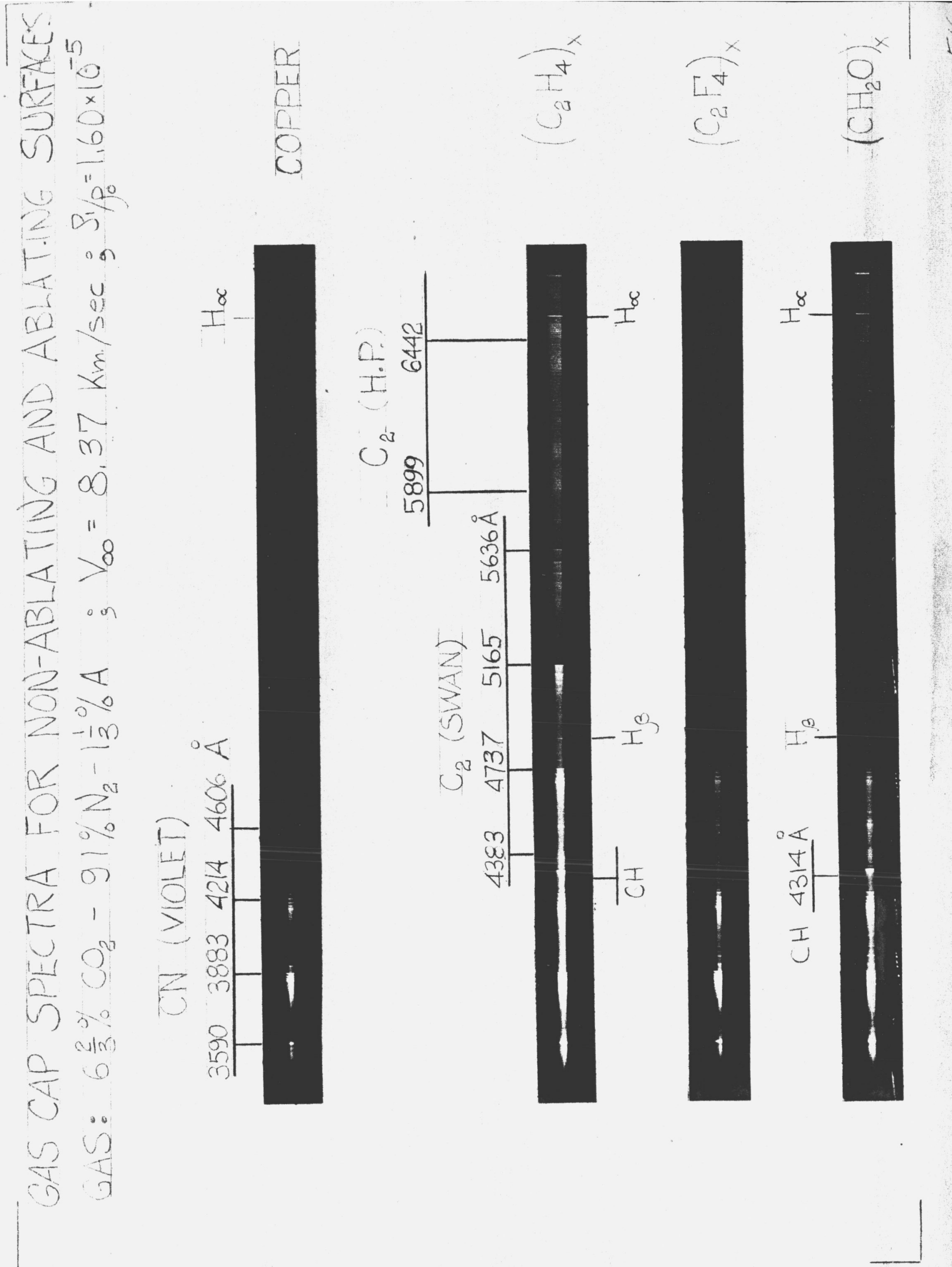




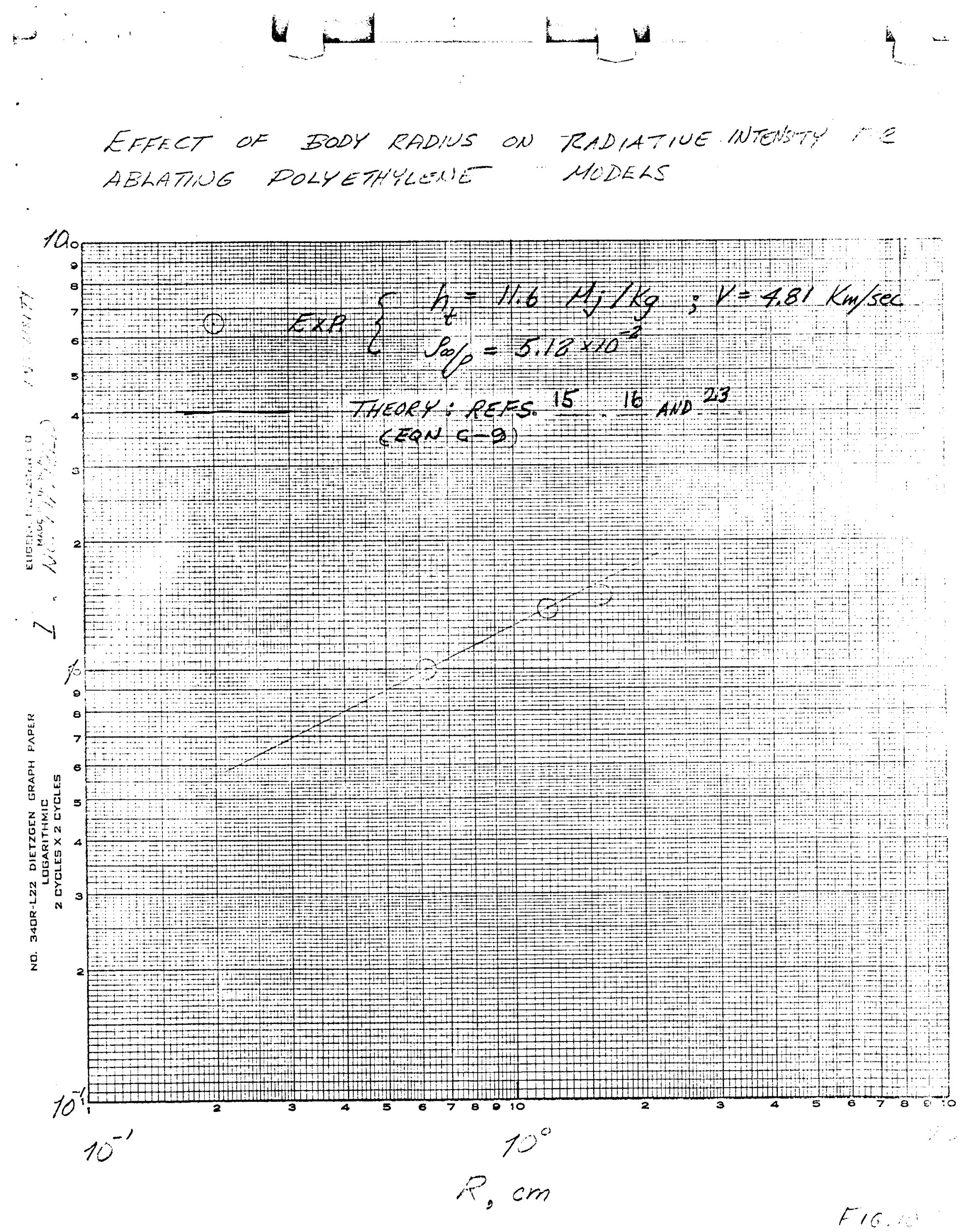



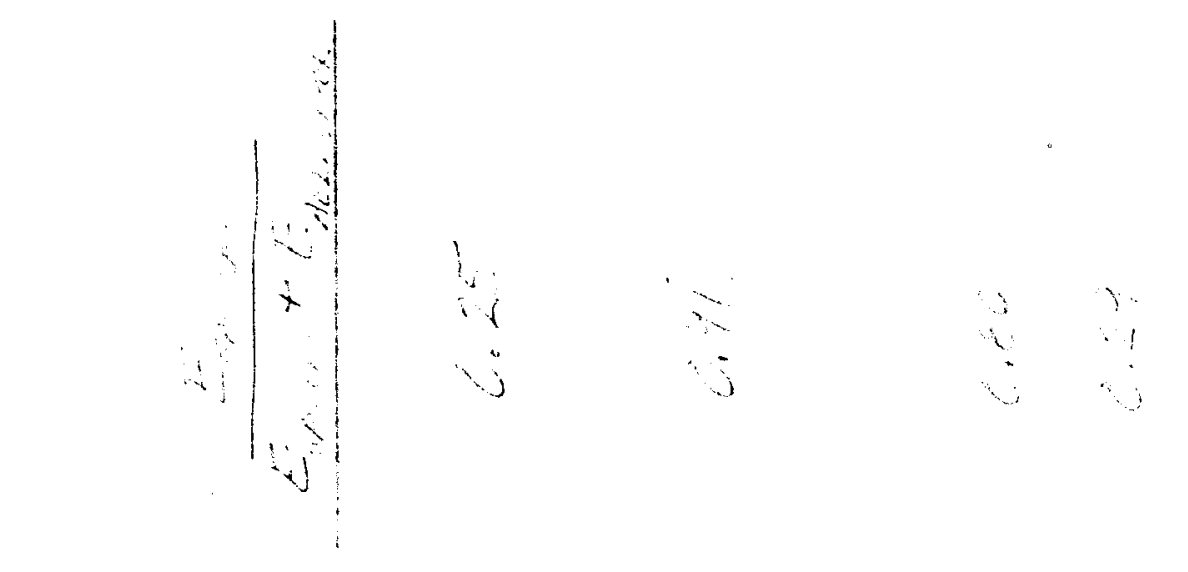

$i$
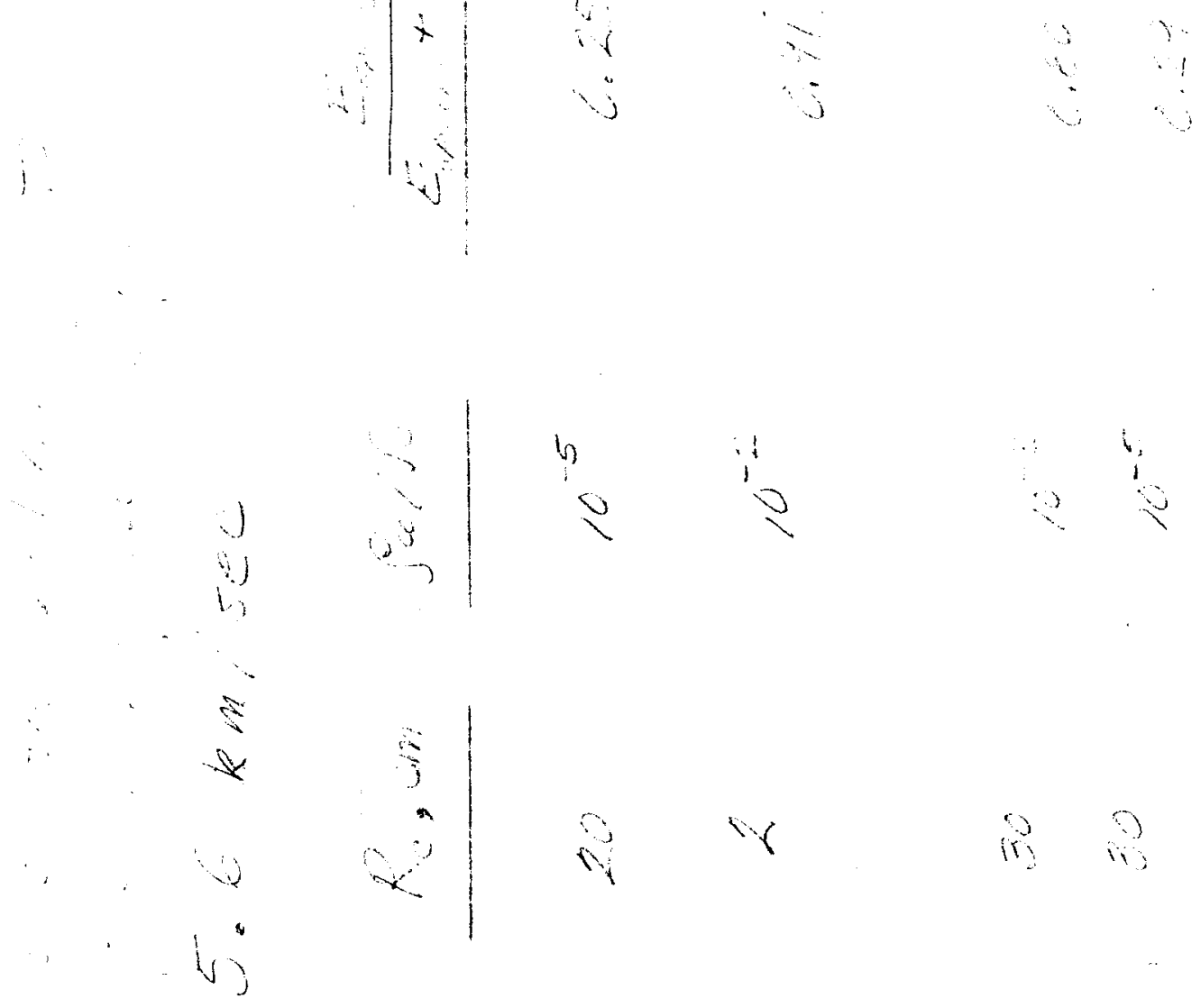

a

i 8

i!

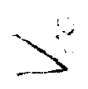

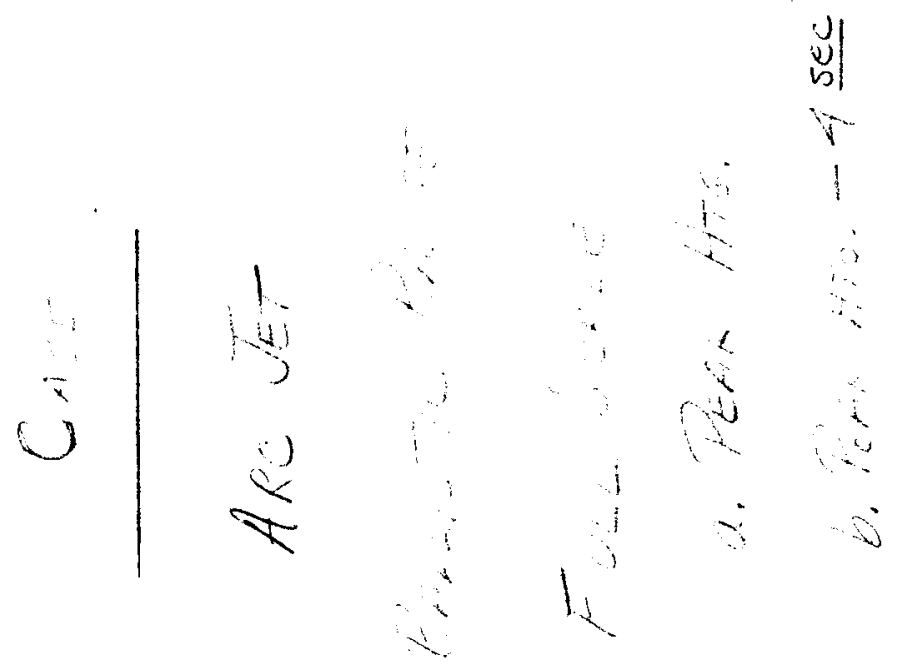



$\dot{m}$

$q_{c}$

$q_{0}$

$\mathrm{R}$

$\mathrm{R}_{\mathrm{c}}$

$\overline{\mathbf{R}}$

$r$ ablation mass loss rate per unit area (gram $/ \mathrm{cm}^{2} \mathrm{sec}$ ) pressure (dynes/ $\mathrm{cm}^{2}$ ) stagnation pressure (dynes/ $\mathrm{cm}^{2}$ ) total energy rate (watts) convective heating rate (watts $/ \mathrm{cm}^{2}$ ) convective heating rate with no ablation (watts $/ \mathrm{cm}^{2}$ ) body rađius $(\mathrm{cm})$; surface reflectivity (App. B) radius of curvature $(\mathrm{cm})$ universal gas constant (erg/gm-mole ${ }^{\circ}$ ) distance between radiating surfaces $(\mathrm{cm})$ absolute temperature $\left({ }^{\circ} \mathrm{K}\right)$; transmissivity wall ablation temperature $\left({ }^{O} K\right)$ velocity $(\mathrm{km} / \mathrm{sec})$ volume $\left(\mathrm{cm}^{3}\right)$ molecular welght ratio

temperature potential parameter ablation constant for material shock stand-off distance $(\mathrm{cm})$ ablation vapor zone thickness $(\mathrm{cm})$ surface emissivity angle determined by lens optics (App. A); angle coordinate (App. B)

thermal conductivity (watts/cm ${ }_{K}$ ) 

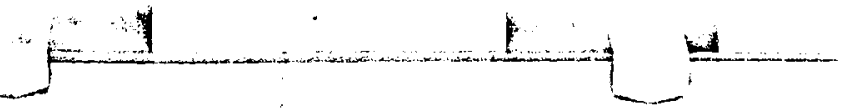

$\lambda$

$\rho$

T

$\varphi \quad .$.

$\Psi$

\section{Subscripts}

$\infty$

0

1

2

3

$a$

E

g

M

T

s

$x$

$\mathrm{y}$

gas cap

calib free stream

reference conditions ( 1 earth atmosphere at $288^{\circ} \mathrm{K}$ )

background region (App. A); lens I (App. B)

region behind normal shock; lens 2 (App. B)

lens 3 (App. B)

aperture

entry

ablation vapor gas

mirror

transmitted beam

tungsten source

surface $x$

surface $y$

value observed when observing gas cap

value observed when observing tungsten source 


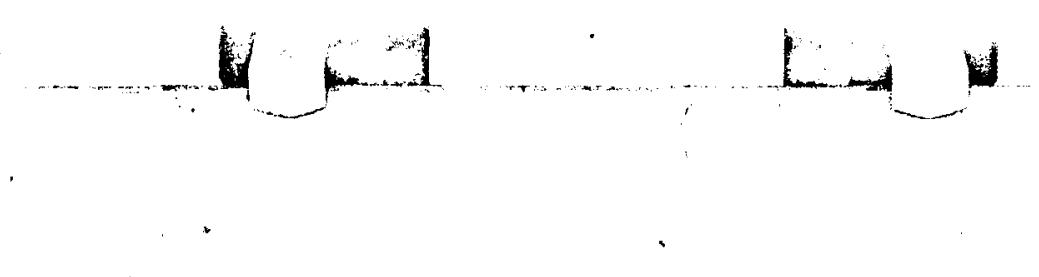

\author{
Appenaix A. Andysis pi collimator for \\ Collection of Gas Cap Radition.
}

\begin{abstract}
In the original amangement for collecting radisit energy a single lens was utilized to view a solid angle of raciating eas, Frigure A-I. As is shown on the figure, radiant enerey was collectea from inside the test body through a small aperture on which the Iens was focused. As will be shown, however, beckground radiation from the arc jet stream ahead of the bow shook wave contributed substantialiy to the total sfgral becsuee the observed volume or gas increases as the cube of the distance from the principal focus. Moreover, the nigh tenperatures and presures that existed upetream in the constrictor of the are jet provided an additional very intense scurce. To reduce this backgrourd signaI, collimation was employed as shoin in Fy gure $A-2$.
\end{abstract}

The behevior of the collimetion aevice, Figure A-2, is compares here Ith that or the system of Fugure $A-1$. To effect a comparison between the two systems, the states of the radiating gas within the resnective vieved rolumes must be estgblished. For simplicity, temperature and density are assumed to be constant behind the bow Ehock wave. The free stream conitions were such that the tenperatwe and density ratios across the bow wave were approximetely equal to 3.0 anc 6.2 respectively. The aencity ratio was determuthed from the observed shook standoff disterce by using the results of Reference 16, and the pressure ratio tas nesured durlng tannel calibration. 


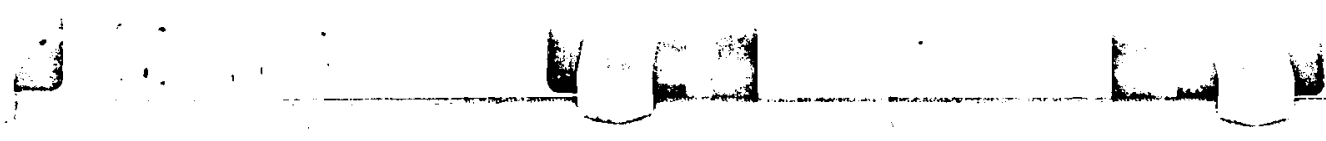

Appendix A $\quad$ - $\quad-2-$

A conservatively low temperature ratio was then obtained from equilibrium charts, Reference 17. The temperature ratio of 3.0 is a result of aissoclation which absorbs about 60 percent of the available thermal energy. The assumption is also made that the gas is transparent.

The total amount of radiation collected is proportional to the number of radiators and their radiative strength. Experimental data (Ref.10) shows that, in the regime of these tests, this quantity can be expressed as

$$
Q \propto \rho^{1 \cdot 4} \vee T^{4}
$$

where $Q$ is total radiated energy, $\rho$ is density, $V$ is the volume seen by the collection system, and $T$ is the absolute temperature.

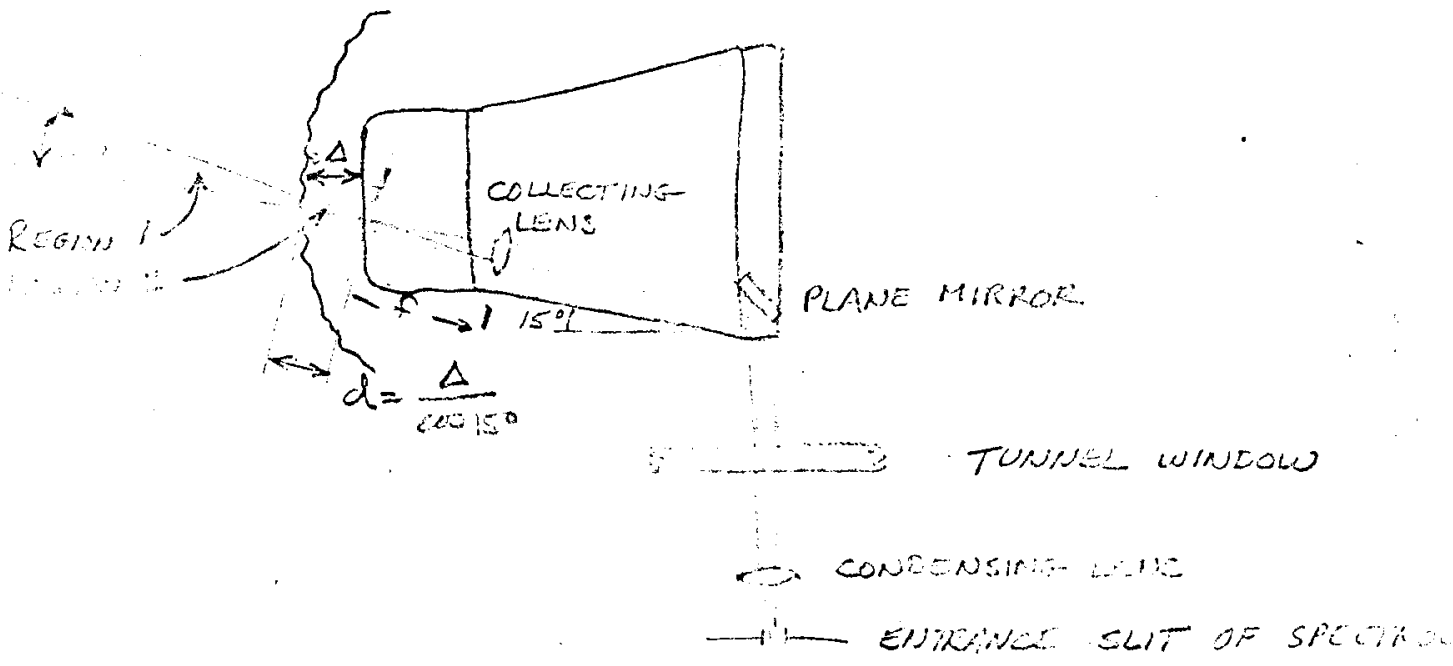

Figure $A-1$ 
$\therefore \therefore-4 f^{1} \cdot 1,1=1=0$

Appendix A

The ratio of gas cap to becherund radiation, corresponding to padiation from region 1 , and reglon 2 of Fimure $A-I$, can be expressed as

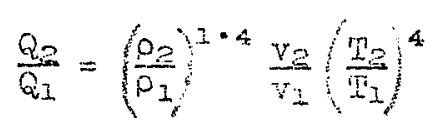

Where the subscripts reier to the regione indicated on the rigure. If $\mathrm{h}$ is the distance from the boy ajong the optical axis, and $A$ the corresponding cross-section wea of the observen rolune, then

$$
v_{2}=\frac{1}{3} A_{2}{ }^{2}=\frac{\pi}{3} a^{3} \tan ^{2} \theta
$$

๕nö

$$
v_{2}=\frac{1}{3} A_{1} n_{2}-v_{2}
$$

Tor the present experimental arrangenent, $\mathrm{h}_{1} \cong 15 \mathrm{a}$, and

$$
V_{1}=1125 \pi 0^{3} \tan ^{2} \theta
$$

The ratio of gas cap to bacigrourid rabiation therefore becomes

$$
\begin{aligned}
\frac{Q_{2}}{Q_{1}} & =(6.2)^{1 \cdot A} \frac{\pi / 3 d^{3} \tan ^{2} \theta}{1125 \pi 0^{3} \tan ^{2} \theta}(3.0)^{4} \\
& =0.32
\end{aligned}
$$

showing that background rediation can contribute up to 75 percent of the total signal.

For the collimeting syeteri show in Figure $A-2$, the ratio of sas cap to backgrouna radietion can be expressed as 

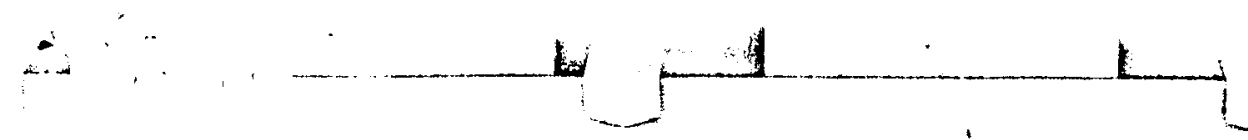

ia

Apperaix A

$-4-$

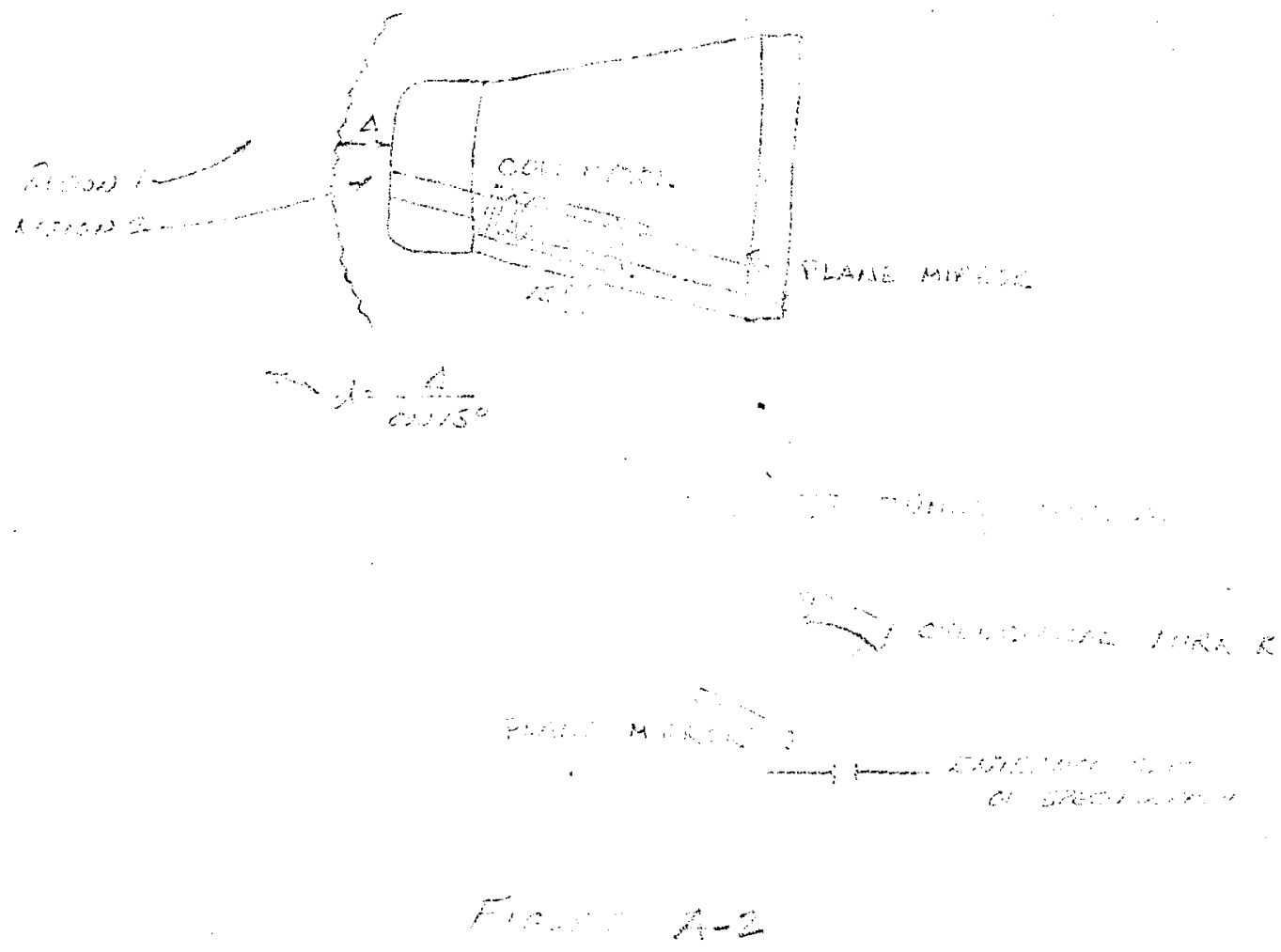

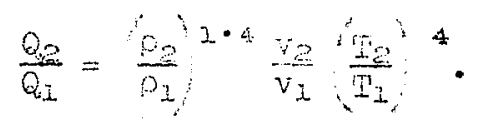

It A is the cross-sectional area of the collimated bean, then

$$
\begin{gathered}
v_{2}=A b_{2}=f d, \text { and } \\
v_{1}=A h_{1}-v_{2} \stackrel{\oplus}{=} 14 \mathrm{Aa}
\end{gathered}
$$

Wine radiation ratio therefore becomes

$$
\begin{aligned}
\frac{Q_{2}}{Q_{I}} & =(6.2)^{2 \cdot 4} \frac{A 0}{14 A C}(3.0)^{4} \\
& =74.4
\end{aligned}
$$




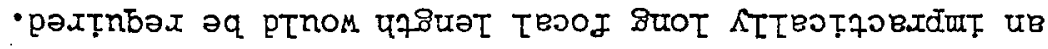

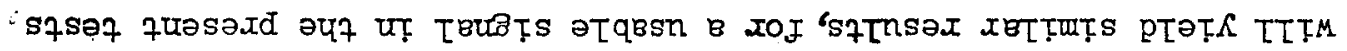

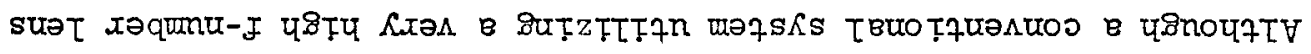

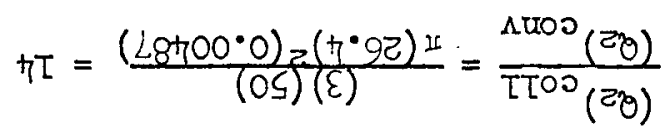

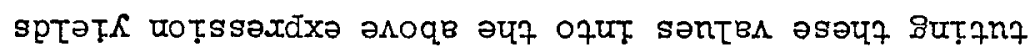

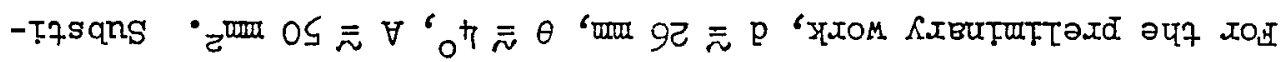

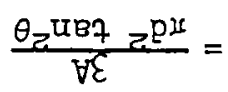

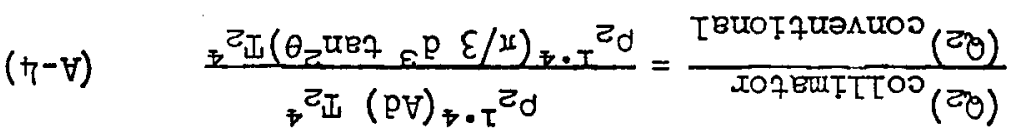

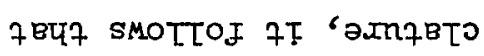

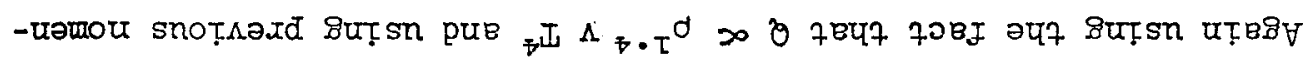

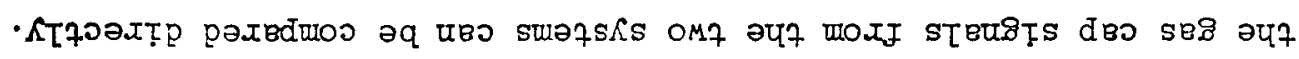

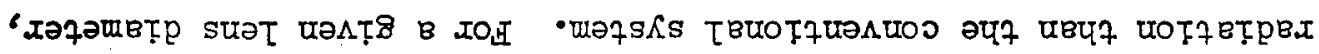

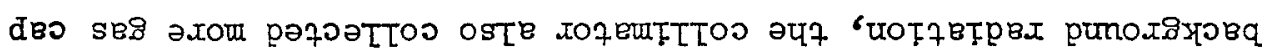

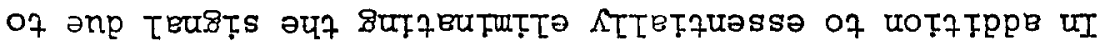

- рәлтәวәл

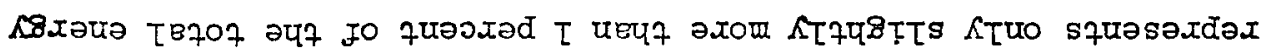

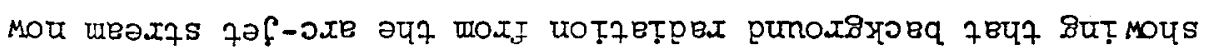

$$
-\zeta-\quad \forall \text { xTpuədd }
$$



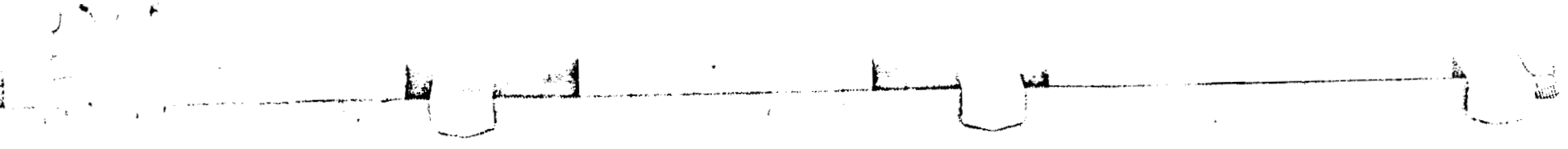

Appenaix B. Calibration for Absolute Intensity

To calibrate for absolute intentities, energy radited from

a tungsten riboon filament lamp was colimated, pussed through

the source collection eystem $(c e$ Apomix A), and focused on the sit of the spectrograph with the test body in place. Floure B-1. shows the arrangement for culibration.
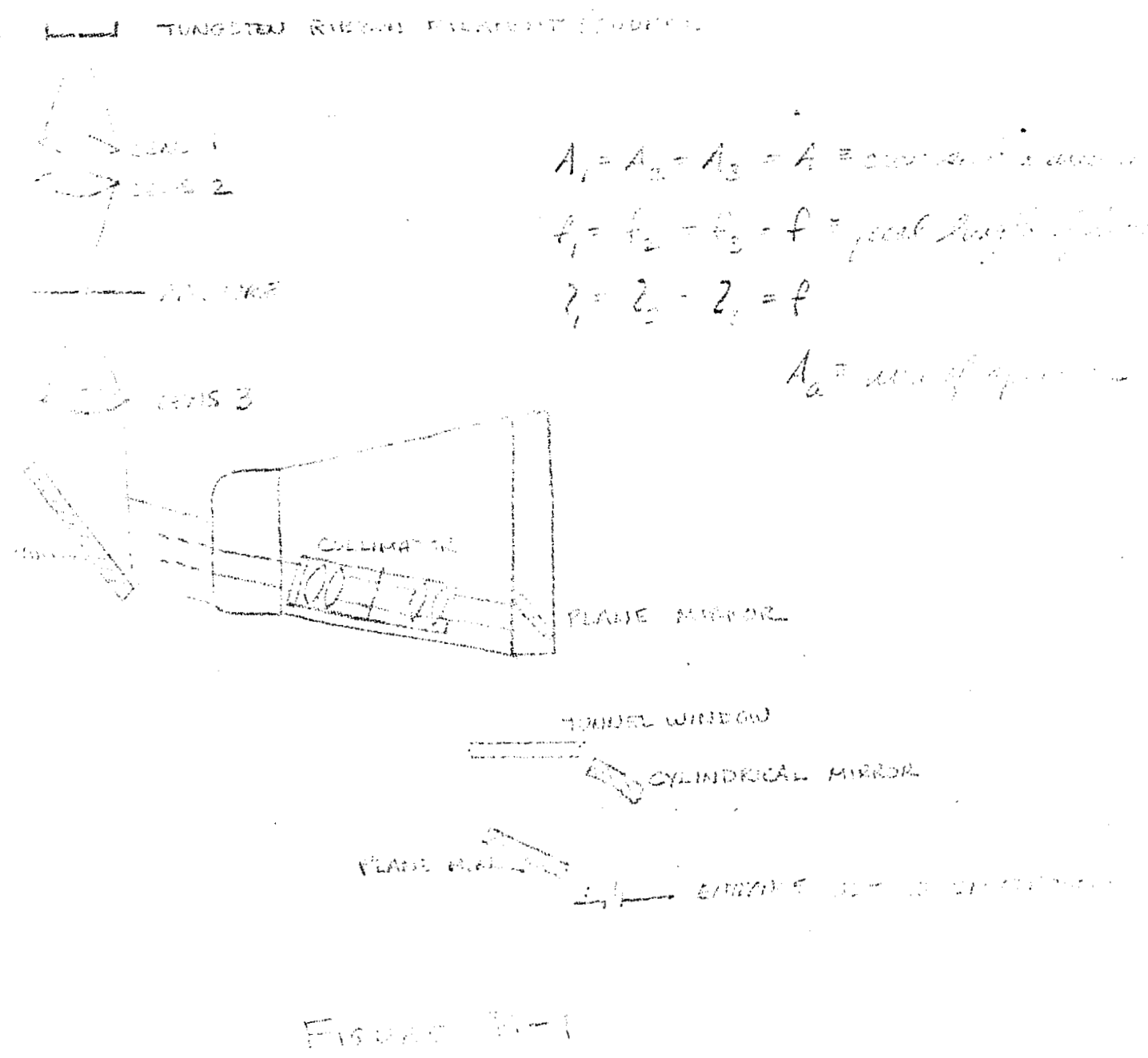


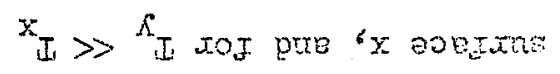

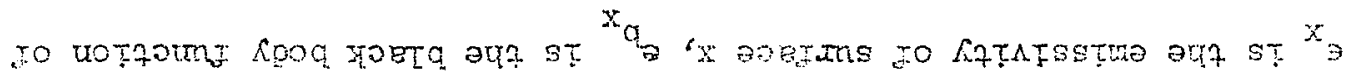

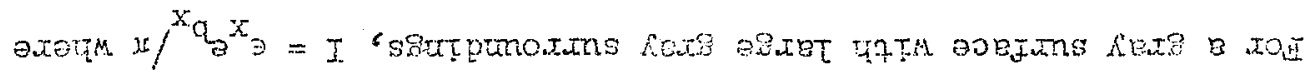

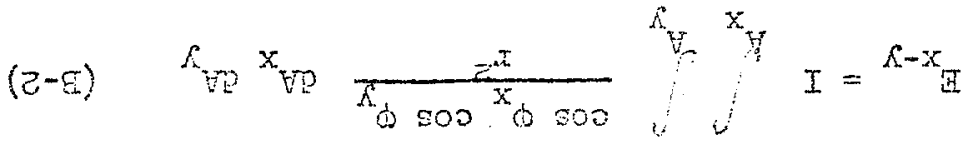

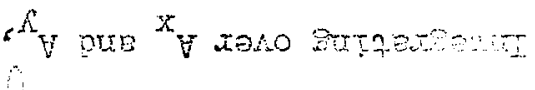

$$
\begin{aligned}
& \text { - } 2.8+9
\end{aligned}
$$

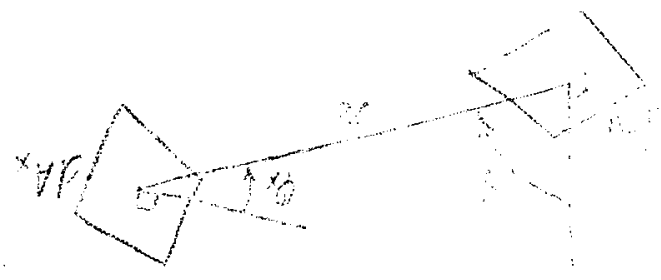

$(\cdot \mathrm{C}-\mathrm{z} \operatorname{sins}$

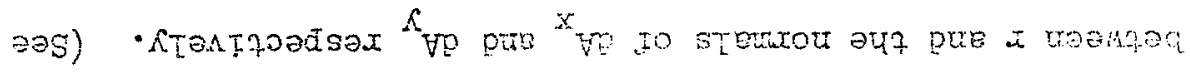

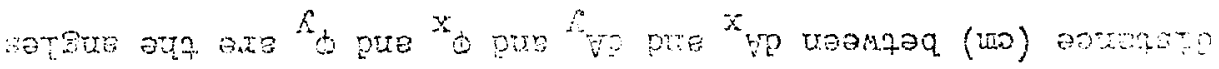

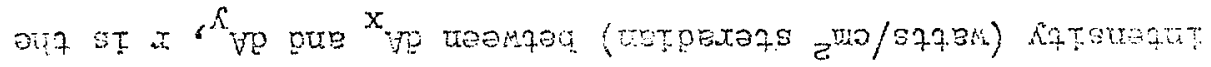

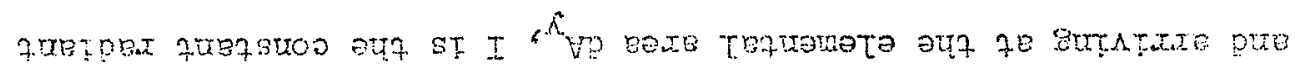

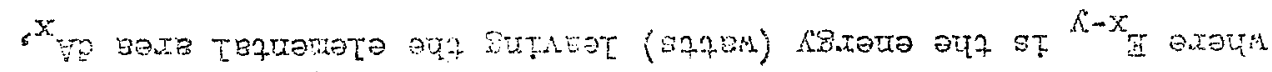

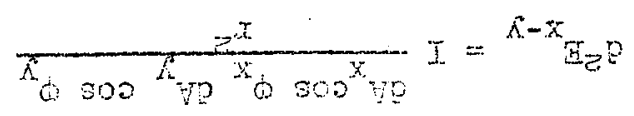

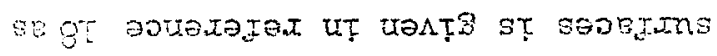

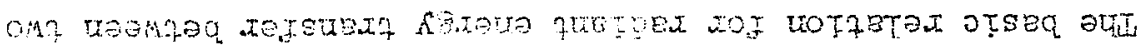

$$
\therefore 2-\quad \text { G xppuodat }
$$




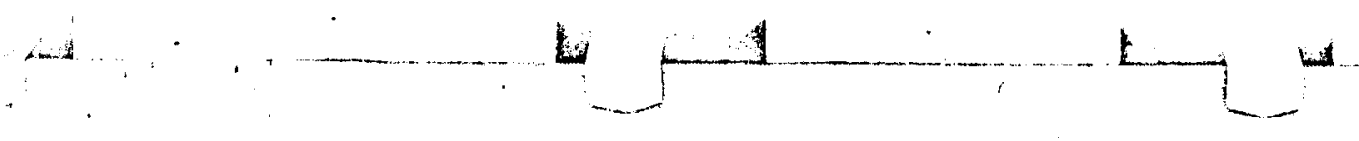

Appendix $B$

$-3-$

$$
\begin{aligned}
& E_{\text {net }} E_{x-y}-E_{y-x} \\
& =D_{x-y}=\frac{\epsilon_{x} e b_{x}}{\pi} \int_{A_{x}} \int_{A_{y}} \frac{\cos \phi_{x} \cos \psi_{y}}{x^{e}} d A_{x} d A_{y}
\end{aligned}
$$

Apriying this relation to the calibration technique wits subsoript

s for the tungsten souree and euscript I for lens I, we have

$$
\Sigma_{i-1}=\frac{\epsilon_{S} \theta_{s}}{\pi} \int_{A_{S}} \int_{A_{1}} \frac{\cos \varphi_{S} \cos \varphi_{1}}{r^{2}} d A_{E} d A_{2}
$$

Whing the usual thin lens approxtmetion that Iens 1 be consiceres

a plene, it rollows thet $A_{3}$ is pirallel to $A_{B}$ so that $\varphi_{3}=\phi_{1}=\phi$. Aso, aince onty the enerey passing through the aperture Aa is usea, then only the energy emanating from this area projected back onto the filament enters the system; and aroe $l_{2}=l_{2}=1$, the substitution thet $A_{S}=A_{a}$ can be made. Reterring to Figure B-3, we see thet, siree the aperture alameter, $a_{a},(=0.54$ ma $) \ll$ the Iens dismeter, $a_{2},(=22.1 \mathrm{~mm})$,

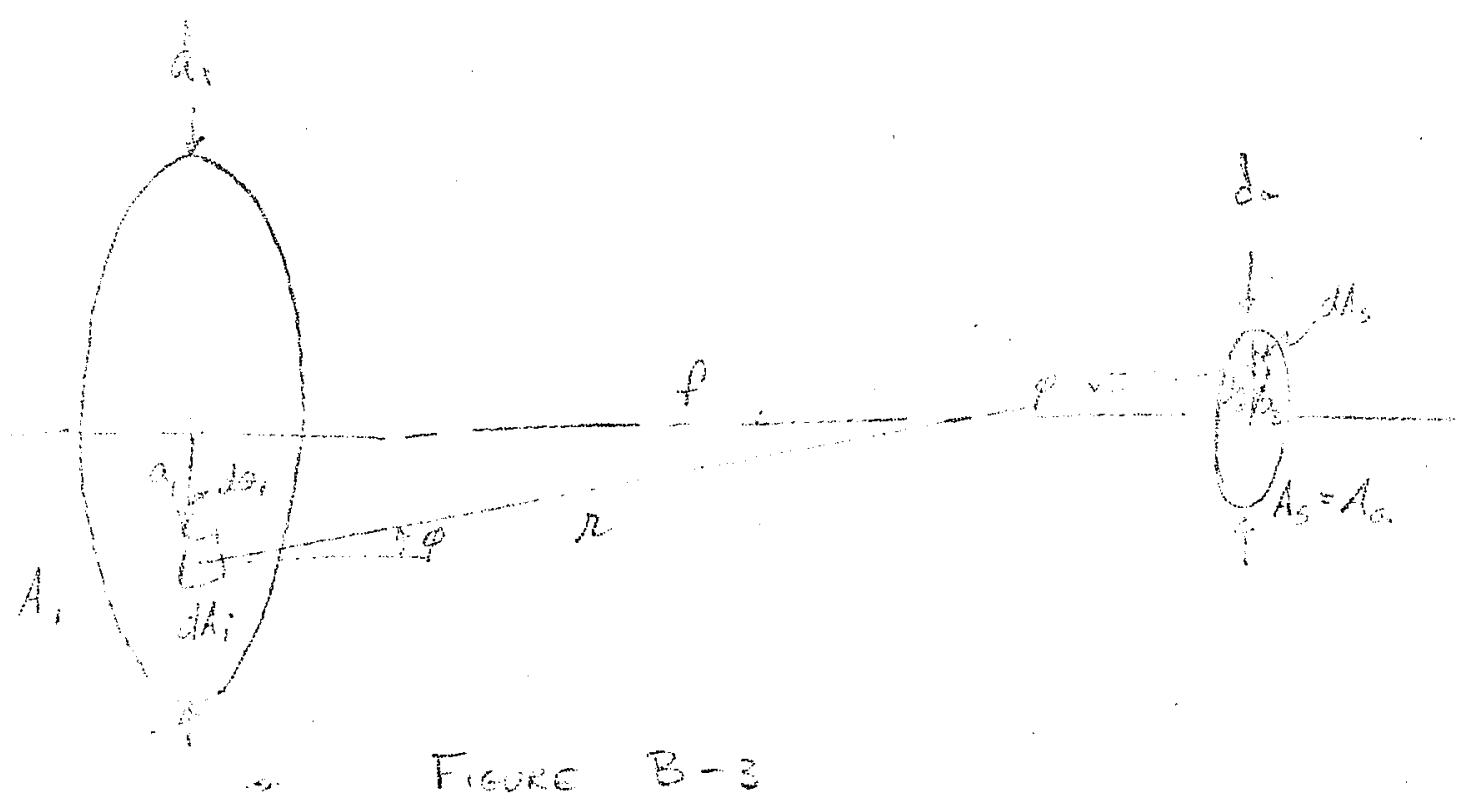




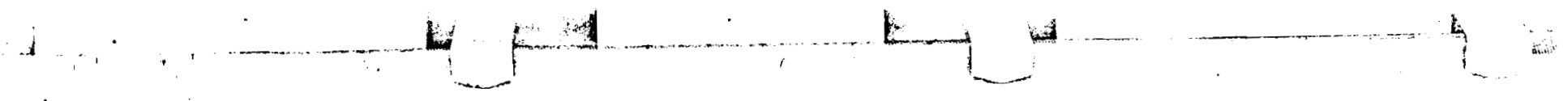

Appendix B

$-4-$

$r^{2}=a_{1}^{2}+f_{1}^{2}$. It followe thet, since cos $p=f r, \cos \theta=$

$f_{I}{ }^{2} /\left(a_{I}{ }^{2}+f_{1}^{2}\right)$. Since $d A_{L}=a_{2} d a_{1} d o_{2}$ and $d A_{B}=a_{5} d \theta_{5} d \theta_{3}$, we now hame

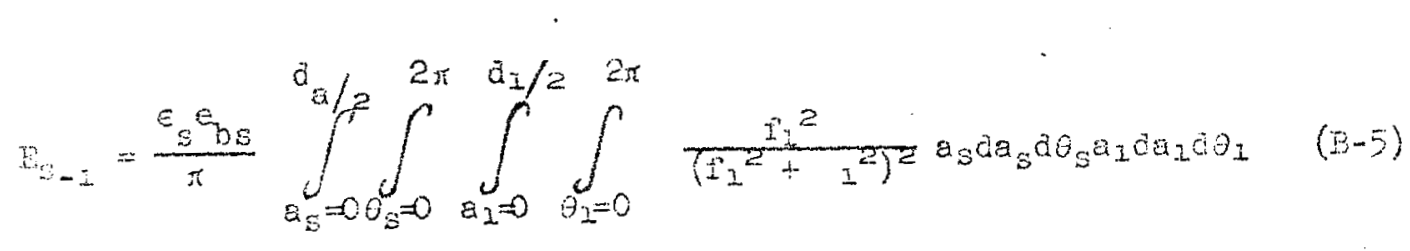

$$
\begin{aligned}
& =\frac{\pi}{4} \frac{a^{2} a_{1}^{2}}{4 I_{1}{ }^{2}+a_{1}{ }^{2}} \epsilon_{5} e_{0 s}
\end{aligned}
$$

Sirce the emiscivity is wavelength cevendent, i.e., $\epsilon_{\mathrm{s}}=\epsilon_{\mathrm{s}}(\lambda)$, we have tinally

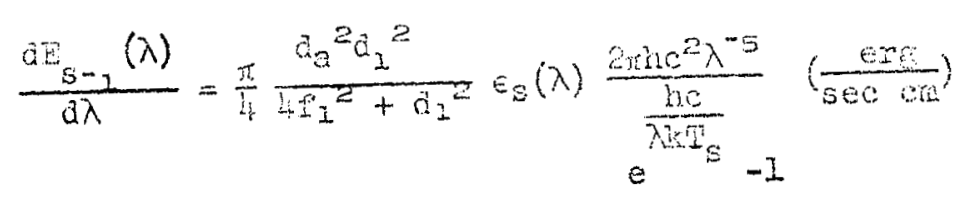

where in $=6.624 \times 10^{-27} \mathrm{erg} e \mathrm{ec},=3 \times 10^{10} \mathrm{em} / \mathrm{sec}, \mathrm{ir}=$

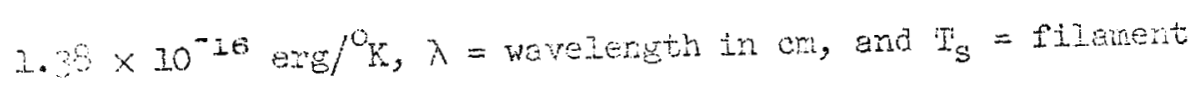

terexture in degres kelvir.

Since all of the reflection and abopption lossed during a test wh vere present durlng the celibration, we need only correct rom loses in the lens and mirror used to coilinate the energy

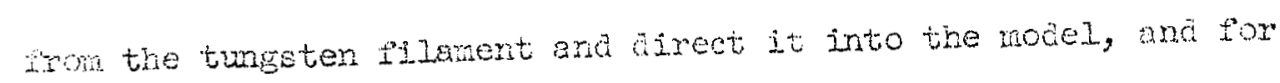
the aiference in area betwen the frejoent bew and the trunswitred (through the model) beam. Letting it be the trensmissivity of a lens, R the replectivity of a wiron, an the diameter of the branciutiod beam, $\left[E_{\text {spect }}(\lambda)\right\}$ the enerey metered by the spectrograph in $\overline{\mathrm{a} \lambda}$, we have 
Apvendix $B$

$$
-5-
$$

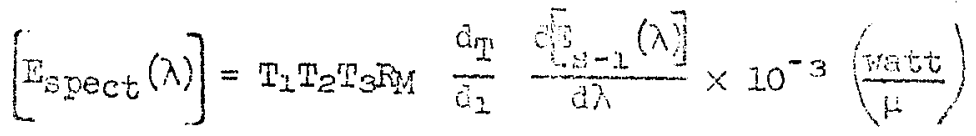

For our calibration procedure, Tintis $=0.653$ (risasure using a 4000 Á pltex with a half width of $300 \AA$ ), $\mathrm{K}_{\mathrm{M}}=0.800$ (measured usire same filter), $d \mathrm{~d}=0.506 \mathrm{~cm}, a_{I}=2.21 \mathrm{~cm}, a_{a}=0.0540 \mathrm{~cm}$ and $I_{2}=0.36 \mathrm{~cm}$, so that

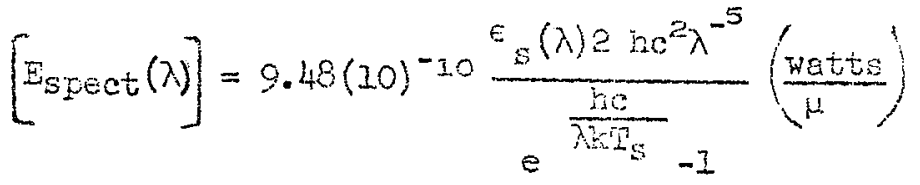

Ts ho detemined by measuring the brightness temperature or the bungten ribbon source with a rilanent-type opticel pyroneter and ourecting to the tme temperature (ref. 19).

The calibration energy vas reluted to the gas cap energy by Ainotidy comparing the heights or ansitoneter traces and exposure vines, $T$, of the obtained spectrographic plates, i.e.

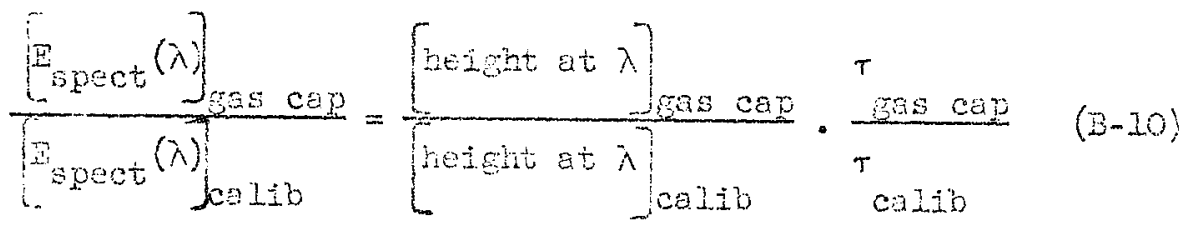

The radiation energy density in the gas cap, $\operatorname{Fe}(\lambda)$, fies then determine? by dividing the weenured anergy by the effective volume of uas seex by the detector optics as in reference 20 . For the jeeent cese, energy was collected fron a constant proparty stagnation region so that the erfective voluris recuces to the actua I observed volune. The value for actual observed volume was aetermined to be $0.481 \mathrm{~cm}^{3}$ and was used to reduce all measurements. Thus, 
J:

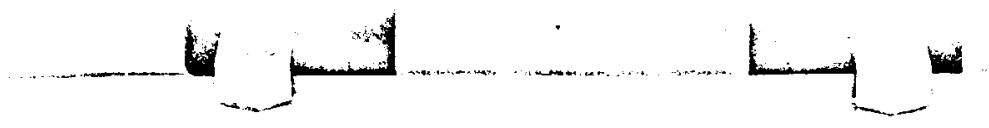

42

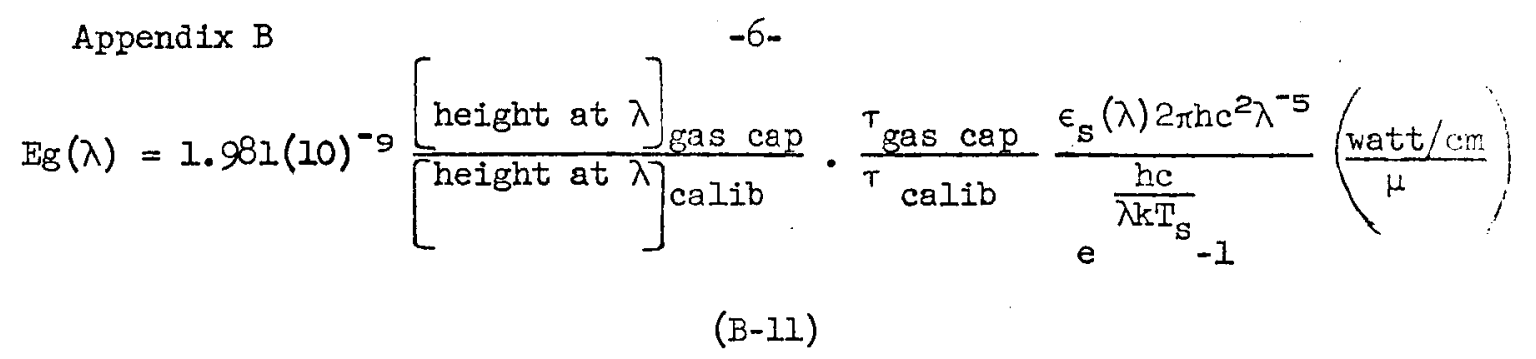

Finally, total energy density was obtained by plotting equation

(B-II) versus wavelength and integrating over $\lambda$. 
$\mu$
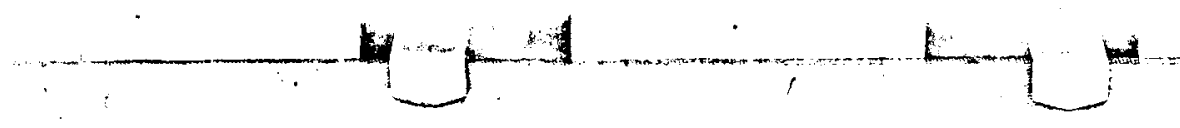

Appendix C. Radiation From Ablation Vapor Zone

The derivation given below is an approximate analysis of the scaling relation that pertains to radiation from the ablation vapor zone. The analysis is for laminar flow at the stagnation region of a hemisphere. However, it should apply. equally well to blunt bodles since these shapes can be characterized as spheres in terms of an equivalent radius of curvature (ref. 2l). For blunt bodies with sharp comers, for example, the equivalent radius of curvature is from 3.5 to 4 times the body radius. The analyeis pertains to a subliming ablator.

Gases either injected (ref. 16) or simply ablated into the stagnation region from material degradation form a alstinct zone separated from the stagnation flow region by an interface. The thickness of this zone can be obtatned from reference 16. Thus,

$$
\frac{\delta}{R_{c}}=\frac{\dot{m}}{g_{\infty} V_{\infty}} \cdot \frac{\Delta}{R_{c}} \cdot \sqrt{\frac{P_{a}}{\rho_{\infty}}} \cdot \sqrt{\frac{P_{a}}{P_{g}}}
$$

For an ablative heat shield, the "erfective heat of ablation" relates the convective heatine rate and the mass ejecta rate to flow conditions and material properties. For subliming ablators this relation is

$$
\frac{q_{c o}}{\tilde{m}}=H_{a}+\beta\left(h_{t}-h_{w}\right)
$$

where $H_{E}$ is the intrinsic neat capacity of the material and the constant $\beta$ depends on the molecular weights of the injecta and oncoming flow. For laminar flow at the stagnation point of a 


\section{Appendix C}

hemisphere, the convective heating rate formulation appearing above is given by (ref. 15) as

$$
q_{c o}=K \sqrt{\frac{p_{t_{2}}}{R_{c}}}\left(h_{t}-h_{w}\right)
$$

Combining equations $\mathrm{C}-1, \mathrm{C}-2$, and $\mathrm{C}-3$ and solving for the ablation vapor zone thickness yields

$$
\frac{\delta}{R_{c}}=\frac{1}{\sqrt{R_{c} \sqrt{\rho_{g}}}}\left\{\frac{K}{\beta\left[1+\frac{H_{a}}{\beta\left(h_{t}-h_{w}\right)}\right]} \cdot \frac{\Delta / R_{c}}{\left(\rho_{\infty} / \rho_{2}\right)}\right\}
$$

However, for hemispheres, the shock stand-off distance can be approximated over wide density ranges by the simple relation (c.f. ref. 22)

$$
\Delta / R_{c}=I /\left(\rho_{2} / \rho_{\infty}\right)
$$

Therefore, the term in equation $\mathrm{C}-4$ within the braces is dependent only on the stagnation enthalpy (or equivalent free-stream velocity). Note that for many comon ablation materials the factor $H_{a} / \beta\left(h_{t}-h_{w}\right)$ is of the order 0.4 for $V_{\infty} \geqq 5 \mathrm{~km} / \mathrm{sec}$. Consequently, the term within the braces is virtually independent of flow conditions and depends primarily on the ablation gas ejecta. Thus,

$$
\delta / R_{c}=K i \sqrt{R_{c} \rho_{g}}
$$

where the definition of $K^{1}$ is given by equation $\mathrm{C}-4$. This last expression indicates that for small scale and/or high density, the thickness of the ablation vapor zone is reduced.

In reference 23 it is shown that for unit mass of ablation products the radiation can be characterized by 


$$
F=k_{2} \rho_{g}^{\xi_{\mathrm{p}} \xi}
$$

where $\mathrm{K}_{2}$ is a constant of the material. The radiation intenstty at the stagnation point can be written as

$$
I=E_{t} \delta=F \rho_{g} \delta=K_{2} \rho_{g}^{I+\xi} T^{\xi} \delta
$$

Conbining equation $\mathrm{C}-8$ with equation $\mathrm{C}-6$ and nomalizing with respect to the density term, one obtains a scaling relation for intensity:

$$
\frac{I}{\left(\rho_{g} / \rho_{0}\right)^{I / 2+\xi}} \propto F_{g}^{\xi} \sqrt{R_{c}}
$$

The terperature of the ablation vapor at the interface is the controlling parameter accoriling to equation $\mathrm{C}-9$ since $\xi$ is typlcally about 3 (ref. 23). Accordingly, a consideration of the dependence of $T_{g}$ or flow conditions is in order.

By approximating the ablation vapor zone by a conoucting fluid layer, one can write $a$ heat balance at the interface between the ablation vapor zone and the stagnation gas regton

$$
\Psi_{q_{0}}=k\left(T_{g} / T_{a}\right) / \delta
$$

the factor $\Psi$ is the heat blockage ratio defined as

$$
\Psi=q_{c} / q_{C O}=E_{Q} /\left[H_{Q}+\beta\left(z_{t}-h_{W}\right)\right]
$$

for subliming ablators. The effect of diffusion between the stagnation zone and the ablation layer zone is contained in the ablation 
ajecta parameter, $\beta$. Solving for the alation vapos gas temperature from equations $\mathrm{C}-3, \mathrm{C}-10$, ans $\mathrm{c}-\mathrm{ut}$, one obtains atter some E.Lebraid manipulation (and wing the usual hypereonic appyoriration $\left.p_{2} \approx p_{t_{2}}\right):$

where:

$$
T_{g} / T_{a}=a / 2+1+(a / 2)^{2}
$$

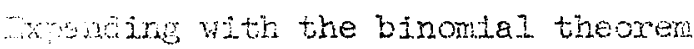

$$
\underline{g}_{g} / I_{a}=I+c / 2+I / 2(c / 2)^{2}
$$

one an verify that fox lon tenperature ablators (polyethylene, Ior armple) only the first two terms are significant in the expansor. Conequenty, to good aproxhation

$$
T_{e} / T_{a}+\alpha / 2
$$

Where a is given in equation $(c-12)$.

Referring to the expression for $\alpha$, note that for a nomalized entiolpy potential $\left[=\left(h_{t}-h_{k}\right) / H_{a}\right]$ of about 8 (i.e., $h_{t}>12 \mathrm{Mj} / \mathrm{kg}$ or $Y_{\infty}>5 \mathrm{~mm} / \mathrm{sec}$ ) the term within the braces is within about 20 percent of the limiting value $(=1 / \beta)$ for usual plastic ablators. It rollow, then, that the tempexature of the ablation vapor is relatively insensitive to the incidert fiow conaltions.

Returning to the scaling; law formulation for the ablation vapor raditive intensity (equation $\mathrm{C}-9$ ), one obtains an approximate 
Anptrolx C

result that holds over wide conditione of incident flow $\left(V_{0}>5\right.$ $\mathrm{km} / \mathrm{sec}$. Namely,

$$
\frac{I}{\left(\rho_{g} / \rho_{0}\right)^{1 / 2}+\xi} \cdots P_{c} \text {, approximately }
$$

Finely, using the relations of equation $\mathrm{C}-8$, the rediation per unit valume is given by

$$
\frac{E_{t}}{\left(\rho_{g} / \rho_{0}\right)^{3+5}}=\operatorname{constant}
$$

Ae noted above (equation $(-14$ ), the dblation vapor terrengture is relatvely inisensitive to flow conditions over wide izuits. Therefore, the alation vapor rediation ger unit volume varies primarily a: lie chation vapor gas density raised to some power dependent m. on the reverial. Velues or 5 are given in reference 23 for ane brical ablation naterials. For exanple, for polyethylene $=2 / 3$. 